\title{
A Decision-making Methodology Integrated in Product Design for Additive Manufacturing Process Selection
}

\begin{tabular}{|r|l|}
\hline Journal: & Rapid Prototyping Journal \\
\hline Manuscript ID & RPJ-06-2019-0174.R1 \\
\hline Manuscript Type: & Original Article \\
\hline Keywords: & $\begin{array}{l}\text { Manufacturing process selection, additive manufacturing, multiple criteria } \\
\text { decision-making, design for additive manufacturing, analytic hierarchy } \\
\text { process }\end{array}$ \\
\hline
\end{tabular}

\section{SCHOLARONE ${ }^{\text {M }}$ \\ Manuscripts}

Authors

Wei Liu

School of Engineering and Applied Science, Aston University, Birmingham, UK Zicheng Zhu

Department of Mechanical Engineering, University of Sheffield, Sheffield, UK Songhe Ye

Department of Engineering, University of Cambridge, Cambridge, UK 


\section{Keywords}

Manufacturing process selection, additive manufacturing, multiple criteria decision-making, design for additive manufacturing, analytic hierarchy process

\section{Introduction}

The ongoing industrial revolution, so called Industry 4.0, has been driven by the continued emergence of novel manufacturing technologies with enhanced manufacturing capability, reduced lead time and production costs (Kamble et al., 2018, Lu, 2017). Additive Manufacturing (AM), as one of the most promising manufacturing technologies, has enabled customised products to be produced in a time and cost effective way (Schmidt et al., 2017). With continued technology development, AM is now available for low to medium volume production 
(Atzeni and Salmi, 2012). However, the plethora of production methods, including AM and traditional manufacturing processes, has become increasingly challenging for designers and engineers to select an appropriate process that are both technically and economically viable. This is due to the fact that the increasingly expanding manufacturing techniques sometimes have different manufacturing properties with each other, which requires a thorough consideration of a wide range of factors such as application areas, product performance and materials, achievable part quality and affordable costs etc. (Zhang et al., 2014).

Design and manufacturing are the two important phases of a product development cycle. There has been a consensus that, in order to reduce the costs incurred resulting from the lack of consideration on the manufacturability of a part, the manufacturing process characteristics should be taken into account during the design process. This integrated practice of designing components while considering their manufacturability is widely recognised as the Design for Manufacturing (DfM) concept (Boothroyd et al., 2002, Hassan et al., 2010). In recent years, with continued advances in AM, the concept of Design for Additive Manufacturing (DfAM) has also been introduced (Thompson et al., 2016). The unique AM process characteristics that are significantly different to traditional manufacturing processes requires the designers and engineers to design the part/product specifically for the AM process to be used. However, most of the decision-making models for process selection developed so far, as shown in Figure 1, can only identify suitable processes based on a given finished part design (Kretzschmar et al., 2018, Fera et al., 2017, Baumers et al., 2017, Zhang et al., 2014, Kim and Oh, 2008). In other words, the decision for process selection is made after the product/part design is complete. This has missed two fundamental issues: (i) it does not enable designers and engineers to design the part/product that is best suited for the manufacturing process in the design stage, by utilising the advantages and circumventing the limitations of the process; and (ii) a part/product that can be additively manufactured does not necessarily mean it should be manufactured by AM in terms of time, cost and quality. The existing AM process selection methods (Mançanares et al., 2015, Fera et al., 2017, Kretzschmar et al., 2018, Wang et al., 2018) look for an appropriate AM process based on the finished part design. Despite the part being technically viable to be made by AM, it may potentially benefit from being manufactured by other manufacturing processes due to cost, surface finish and lead time.

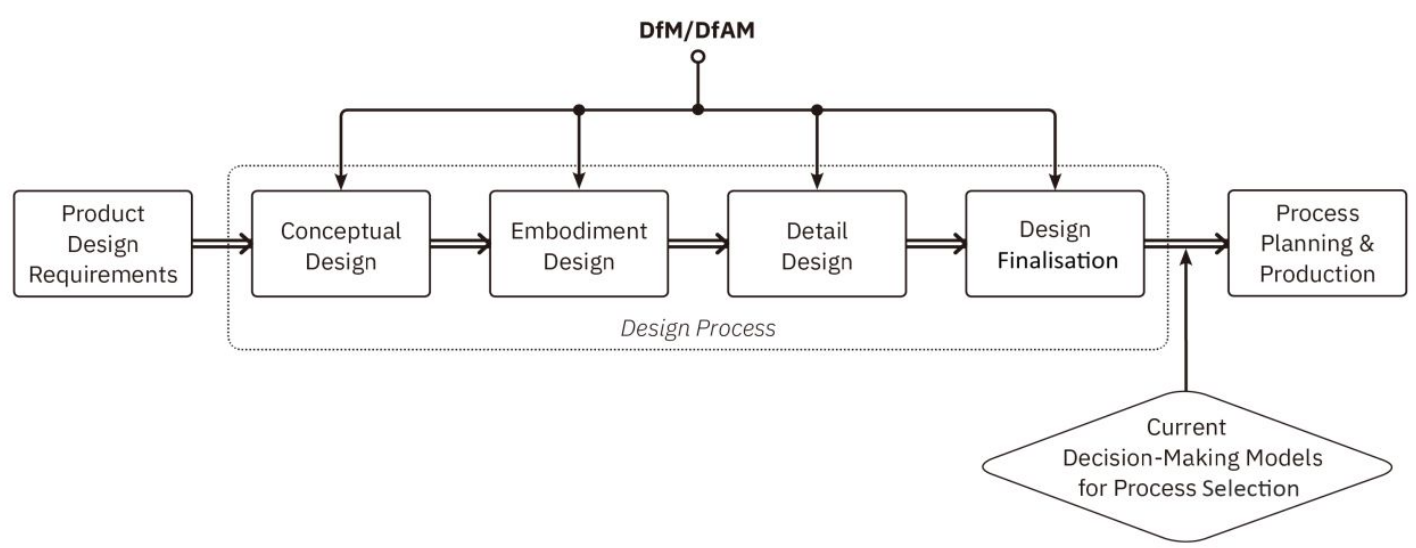

Figure 1: The typical process of design, process selection decision-making and manufacture adapted from (Wright, 1998, Khaleeq uz Zaman et al., 2017) 


\section{Literature review}

The decision for choosing a manufacturing technology for a specific product is primarily based on cost in industrial practise (Kamps et al., 2018, Jiang et al., 2017). Therefore, the majority of the state-of-the-art research on manufacturing process selection focuses on selecting a process that requires either the lowest production costs or the shortest production time. Typically, a Multi-Criteria Decision-Making (MCDM) technique (Majumder, 2015) such as Analytic Hierarchy Process (AHP) or Technique of Ranking Preferences by Similarity to Ideal Solution (TOPSIS) is used to choose the best alternative given a finite number of criteria (Khaleeq uz Zaman et al., 2017).

Kretzshmar et al. (2018) developed a decision support system to evaluate productivity i.e. production time and cost) of powder-bed fusion metal AM processes. The user is allowed to choose accuracy level, production volume and support structure density, together with the Standard Triangle Language (STL) file as the input parameters. Fera et al. (2017) developed a time and cost calculation model that estimates the build time and costs of Steroreolithography (SLA), Selective Laser Sintering (SLS) and Electron Beam Melting (EBM) processes. He et al. (2019) evaluated the design from the product sustainability aspect, providing assistance for process selection. Kamps et al. (2018) assessed production cost and product life cycle for producing a gear wheel using machining, hobbing and Selective Laser Melting (SLM). Atzeni and Salmi (2012) evaluated the economic production volume for metal AM techniques by comparing with die casting. A generic decision methodology for AM materials and process selection, based on AHP theory, is proposed by Zaman et al. (2018). It seeks to find the best combination of AM materials, processes and commercial machines based on a given part design. In the paper by Zhang et al. (2014), a method based on measuring manufacturing knowledge value is presented, identifying suitable AM processes in terms of cost, time and part quality. Khajavi et al. (2018) analysed the impact of Titanium alloys as the raw material on the overall costs of SLM, machining and casting. Kopf et al. (2018) proposed a cost-orientated method for planning SLM equipment for series production lines. Zhu et al. (2016) developed a build time estimation model to calculate the time needed in printing objects in FDM. Baumers et al. (2017) studied the build volume capacity utilisation for the SLM process. A cost model was developed, evaluating four aspects: SLM machine capacity utilisation, ancillary process steps, cost effect of build failure and design adaptation. Baldinger et al. (2016) applied an analogical cost estimation method to estimate costs based on production volume and average packing ratio. Rickenbacher et al. (2013) also developed a similar cost model to assess the costs of SLM parts. 
Hassan et al. (2010) presented a quality and cost-based conceptual process planning approach to facilitating decision making of manufacturing process selection.

Research has also been undertaken to optimise the existing Multi-Criteria Decision-Making techniques. Wang et al. (2018) developed a decision support system with an optimised the TOPSIS algorithm for AM process selection. Justino Netto et al. (2019) used the AHP algorithm to select low-cost Fused Deposition Modelling (FDM) printers $(<\$ 5,000)$. Lukic et al. (2017) developed a MCDM system for manufacturing process selection. The system is set with 10 criteria, assessing various aspects of a manufacturing process such as economic production volume, dimensional accuracy, cycle time and operating costs. Mançanares et al. (2015) introduced an AHP-based process selection method for selecting AM technologies and machines. Armillotta (2008) developed an AHPbased decision model that ranks AM processes for different types of application, namely making conceptual models, technical prototypes and pilot production runs. Chakladar and Chakraborty (2008) combined TOPSIS with AHP in a decision-making system for selecting non-traditional machining processes e.g. ultrasonic machining and electrochemical machining. Favi et al. (2018) explored a multi-objective design approach to assist designers to choose the most feasible design option in conceptual design stage. In the paper by Zhu et al. (2017), a decisionmaking logic was presented which was able to intelligently schedule AM and machining operation sequences. Ndip-Agbor et al. (2018) proposed a concept for selecting manufacturing processes and scheduling process sequences, based on product geometry and quality specifications, in the context of autonomous cyber-physical systems. Adhikari and Mirshams (2017) generalised the Ashby's materials selection approach (Ashby et al., 2004, Ashby and Johnson, 2013) for choosing suitable Aluminium and Magnesium alloys for the design of light weight aircraft structures. Zha (2005) applied a fuzzy logic algorithm to a decision-making tool that is able to evaluate manufacturing processes and materials in terms of production costs in conceptual design stage. Yim and Rosen (2012) developed an approximate model for estimating the cost and build time of AM processes.

From the above literature review, it can be identified that, the majority of the decision-making models for AM process selection is applied at the end of the design process, namely, the decision-making takes place upon a finished design and identifies an AM process, as shown in Figure 1. Despite the selected AM process being technically able to produce the part/product, it might not be the most suited manufacturing process compared with other traditional processes in terms of lead time, cost for volume production and surface roughness etc., such as some example parts shown in the papers by Kretzschmar et al. (2018) and Fera et al. (2017). Moreover, in the process selection methods presented in the literature, especially the methods for AM process selection, choosing a manufacturing process is usually performed at the end of the design process. This does not facilitate the designers to utilise DfM/DfAM principles to take advantages and circumvent the drawbacks of the manufacturing process to be used. Hence, this study aims to address this issue by developing a decision-making methodology that is integrated in the design process. 


\section{The new decision-making methodology for process selection}

The overall structure of the new decision-making methodology is introduced in Section 4.1, which is followed by the description of the five major elements in the succeeding subsections.

\subsection{The structure of the decision-making methodology}

In order to improve design efficiency and generate effective product designs, as introduced in Section 1, designers need to have a manufacturing process in mind in early design stage and then to design the product that is best suited for this specific process (Boothroyd et al., 2002, Thompson et al., 2016). The decision-making methodology 
integrated in the design process is shown in Figure 2. It consists of four key elements, which are implemented in sequence along with the design process:

(i) Initial screening of manufacturing processes

(ii) Technical evaluation and selection of feasible manufacturing processes

(iii) Re-evaluation of the feasible processes

(iv) Production machine selection in terms of manufacturing costs

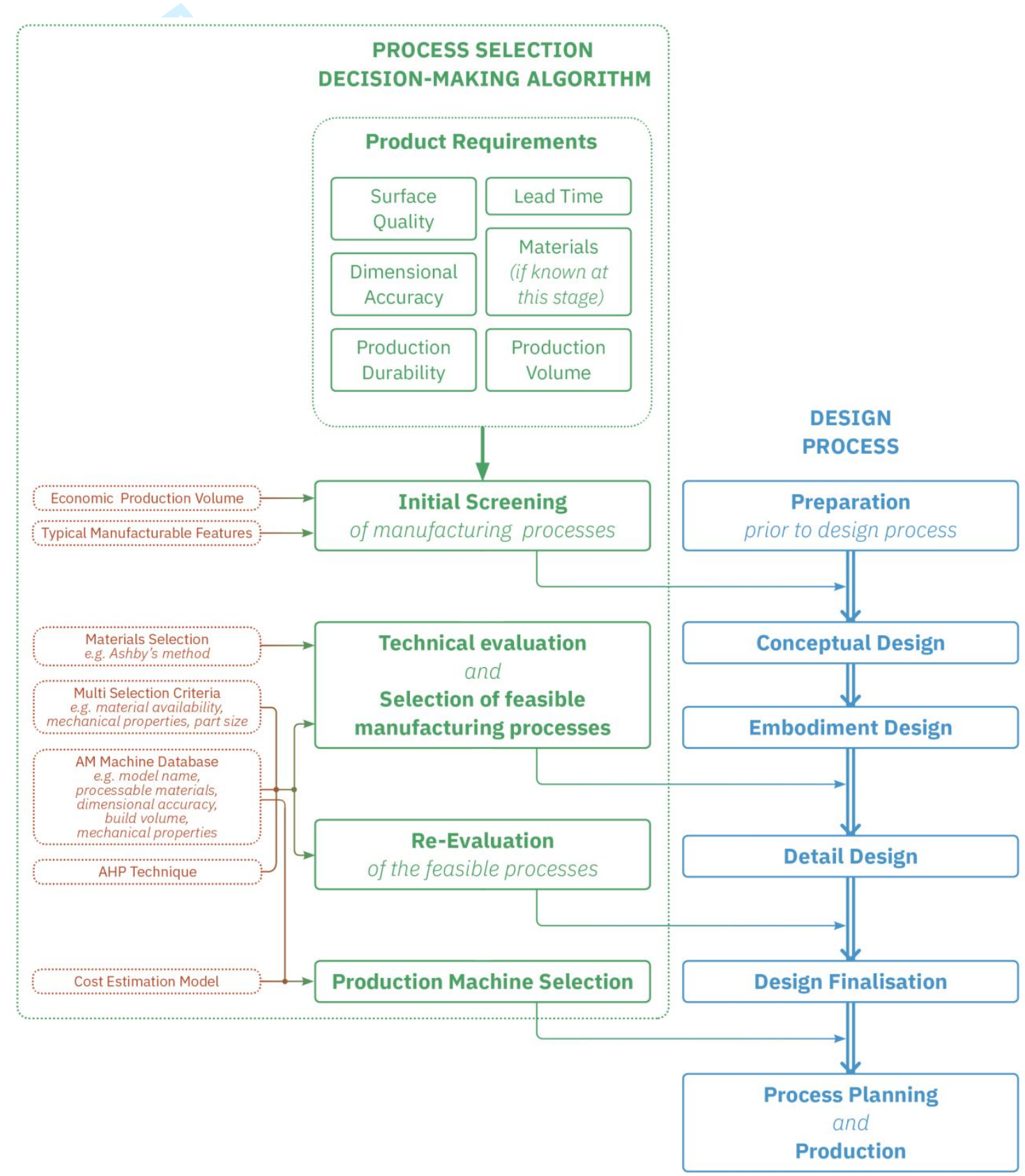

Figure 2: The developed decision-making methodology

The methodology starts with an initial screening of manufacturing processes (element i) based on the must-have product/part requirements e.g. level of dimensional accuracy, number of products to be produced and lead time. These requirements are generally specified by the client before commencing the design process. The initial 
screening can promptly rule out processes that are neither technologically or economically viable, and identify whether AM production is a viable route to meet the client's requirements. The designer/engineer then develops a few design concepts in the conceptual design stage, which are further developed into the embodiment design stage. Based on the design so far, the surviving AM processes are evaluated and selected (element ii), using Analytical Hierarchy Process method where a number of selection criteria are applied, which will be presented in Section 4.3. Upon deciding the process to be used, the designer will further develop the product/part design from embodiment to detail design. As the design is progressing towards finalisation, the manufacturability of the designed product will be assessed (element iii), identifying unsuitable features, which might have been designed during the sophisticated design process. These features would cause potential failure in manufacturing or increased production time and costs. A features set developed by the authors is provided for the designer to consider, facilitating the design process. Having finalised the design, a number of commercially available machines (element iv) that are capable of producing the product/part are ranked and selected. A database is constructed, which contains specifications of the over 200 commercial AM systems. The decision-making methodology aims to assist the designers/engineer to (1) first identify whether the part should be designed for AM production, (2) choose the appropriate AM process, facilitating the design process, and (3) select the suitable AM production system based on the finalised design.

\subsection{Initial screening of manufacturing processes}

In this stage, an initial screening process takes place to identify if AM is feasible for the intended application from technical capability and economic viability aspects. In order to identify the selection criteria, a qualitative research method was employed. This is different to the research work reported in the literature where the selection criteria are usually determined by the paper authors based on their experience, which can be somewhat subjective. This study carried out an online survey of 50 professional designers and 13 structured face-to-face interviews with 16 professional designers with at least 5 years' experience in product design and DfAM. This identified the selection criteria that were most frequently used prior to the design process or in early design stages. These criteria considered in the initial screening are listed below:

- production volume

- lead time

- dimensional accuracy

- $\quad$ surface quality

- product durability

The user interface of the initial screening is shown in Figure 3, where the designer is allowed to define the design priorities, specify the production volume, lead time and material (if known in this stage) to be used. The priorities include specific dimensional accuracy, surface quality (in terms of surface finish Ra) and durability. These priorities together with production volume and lead time are usually defined in the product requirements by the client. In addition, if the designer is certain that there are some feature shapes that will definitely be needed in the final 
product to achieve required product functionality, he/she can also specify them by uploading a STL file. This will facilitate the process selection. The production lead times for AM and vacuum casting are usually 4 weeks whereas for injection moulding, machining and extrusion, the lead times are 8-12 weeks. The product durability is another important factor to address before proceeding to the design process. The product durability was repeatedly mentioned in the interviews, and it has been recognised as an inherent drawback for plastic AM parts as compared to injection moulded counterparts. A citation from an interviewee was that 'SLS parts can easily be affected by moisture, sunlight and other elements in air. In terms of appearance, Nylon parts are white but they may become yellow over time. SLA resin is not stable either, or even worse. In general, their durability is much poorer than other normal plastics.'

\begin{tabular}{|c|c|c|c|}
\hline \multicolumn{2}{|l|}{ I의 Initial screening } & \multicolumn{2}{|c|}{$-\square \quad \square$} \\
\hline \multicolumn{2}{|c|}{ Please select the following: } & \multicolumn{2}{|r|}{ (3) Help } \\
\hline \multicolumn{2}{|c|}{ Production volume (unit) } & \multicolumn{2}{|l|}{ Material (Please tick and select) } \\
\hline $1-10$ & $\nabla$ & \multicolumn{2}{|l|}{$\square$ Material to be used is not } \\
\hline \multicolumn{2}{|c|}{ Lead time (weeks) } & determined at this stage. & \\
\hline$<4$ weeks & $\nabla$ & \multirow{2}{*}{$\begin{array}{l}\text { Material to be used has } \\
\text { been determined. }\end{array}$} & \\
\hline \multicolumn{2}{|c|}{ Dimensional accuracy (mm) } & & \\
\hline Medium & - & \multirow{2}{*}{ Stainless steel } & \\
\hline $0.05-0.15 \mathrm{~mm}$ & - & & \\
\hline \multicolumn{2}{|c|}{ Surface quality $(\mu \mathrm{m})$} & \multirow{3}{*}{ Upload st file } & \\
\hline High & $\nabla$ & & \\
\hline$<2 \mu \mathrm{m}$ & - & & \\
\hline \multicolumn{2}{|c|}{ Product durability (year) } & \multirow[t]{3}{*}{$\square$ Stl file is not available. } & \\
\hline Low & V & & \\
\hline$<5$ years & $\nabla$ & & \\
\hline
\end{tabular}

Figure 3: The input parameters for initial screening

The dimensional accuracy, surface quality and product durability are classed into three levels, i.e. high, medium and low, as shown in Table 1. In order to establish the economic production volume for AM (Atzeni and Salmi, 2012), a number of parts are designed with varying sizes, ranging from $5 \times 10^{4} \mathrm{~mm}^{3}, 5 \times 10^{5} \mathrm{~mm}^{3}$ and $5 \times 10^{7} \mathrm{~mm}^{3}$, which represents small, medium and large part sizes for AM. Some of the parts were designed to be manufacturable by injection moulding (IM) and vacuum casting (VC), and some were designed to be manufacturable by machining and extrusion. Two example parts are shown in Figure 4, representing small and medium part sizes. These two parts can be manufactured by AM, machining, IM and VC in different materials such as Polyamide 12 and Aluminium 6061. The part shown in Figure 4a is a flat disc, which can be additively manufactured in a relatively short period of time and with a low cost whilst achieving a high level of surface quality. Machining is also time-efficient but longer set up time would be needed. The part in Figure 4b is the opposite, which would require a long build time due to the height if it were to be made by AM, and would be highly challenging for machining. On the other hand, it IM and VC would be ideal candidates but the production volume would be a main limitation for these two techniques. In total, 10 AM service bureaus based in the UK 
were approached and requested for quotation for producing these parts for quantities of 1, 10, 50, 100 and 1000 units. The average unit costs of the example parts in Figure 4 manufactured by FDM, SLS, Injection Moulding and Vacuum Casting are plotted in Figure 5 and Figure 6. It is noted that the production volume starts with 25 units for injection moulding and vacuum casting as they are not common methods for one-off part production. The 25 units were the minimum order quantity that the service bureaus were able to achieve. In general, the economic production volumes for plastic AM processes for a small, a medium and a large size of the part are less than 100, 80 and 10 units. This indicates, if the expected quantities to be produced are more than the economic production volume of the specific AM process (e.g. to produce 200 small parts), injection moulding or vacuum casting will be a better option in terms of production costs. The same approach was applied to identifying the economic production volumes for metal AM processes. Example parts were sent to the AM service bureaus to request production costs in relation to production volume. The cost per item was then calculated. By doing so, the economic volume was found to be 200, 50 and 20 units for a small, a medium and a large size, respectively. It is worth mentioning that, for initial screening, an accurate model of economic production volumes for AM is not necessary as this step is aimed at providing a fast way to determine whether AM production is viable based on the design requirements.

Table 1: Summary of levels of selection criteria in initial screening

\begin{tabular}{|l|l|l|l|}
\hline \multirow{2}{*}{ Selection criteria } & \multicolumn{2}{c|}{ Level } \\
\cline { 2 - 4 } & \multicolumn{1}{|c|}{ High } & \multicolumn{1}{c|}{ Medium } & \multicolumn{1}{c|}{ Low } \\
\hline Dimensional accuracy & $<0.05 \mathrm{~mm}$ & $0.05-0.15 \mathrm{~mm}$ & $>8 \mu \mathrm{m}$ \\
\hline Surface quality $(\mathrm{R} a)$ & $<2 \mu \mathrm{m}$ & $2-8 \mu \mathrm{m}$ & $<5$ years \\
\hline Durability & $10+$ years & $5-10$ years & \\
\hline
\end{tabular}

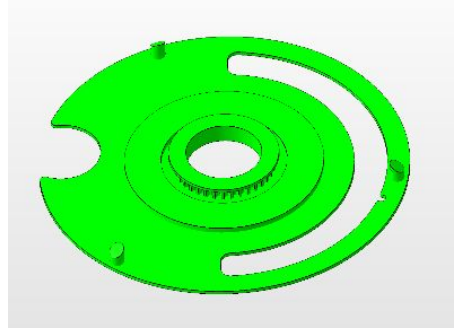

(a)

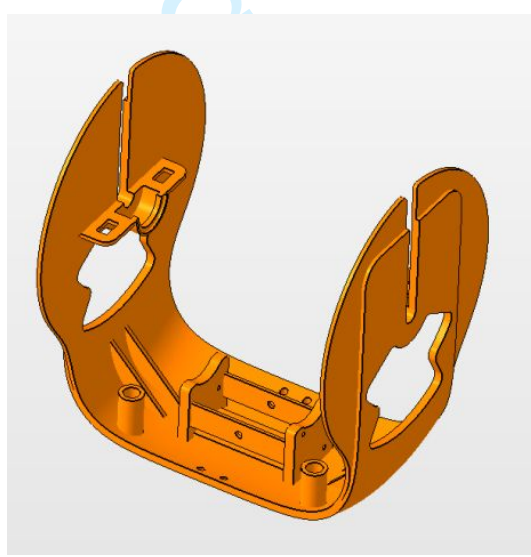

(b)

Figure 4: Two example parts used for identifying economic production volume for AM 


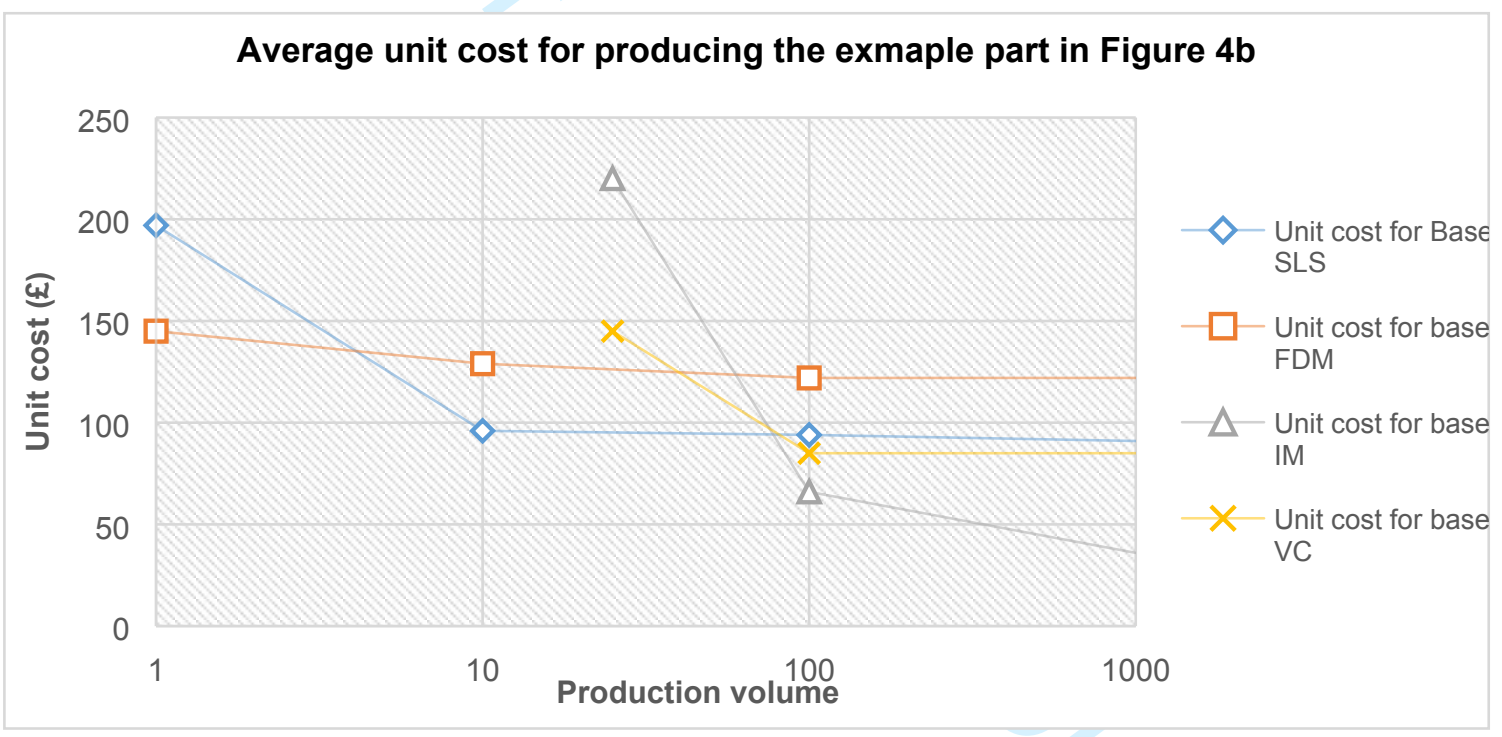

Figure 6: The average unit cost for producing the example part in Figure 4b

Part of the selection matrix that is used in the initial screening stage is shown in Table 2. Please note that for some processes e.g. SLM, the dimensional accuracy may fall into both high and medium range, depending on the commercial SLM system to be used. The product durability for SLM and EBM is unknown as there has not been established data to support this. 
Table 2: Part of the selection matrix for initial screening of manufacturing processes

\begin{tabular}{|c|c|c|c|c|c|c|c|c|c|c|c|c|c|c|c|c|c|}
\hline \multirow[b]{2}{*}{ Process } & \multicolumn{3}{|c|}{$\begin{array}{l}\text { Dimensio } \\
\text { nal } \\
\text { accuracy }\end{array}$} & \multicolumn{3}{|c|}{$\begin{array}{l}\text { Surface } \\
\text { quality }\end{array}$} & \multicolumn{3}{|c|}{$\begin{array}{c}\text { Product } \\
\text { durability }\end{array}$} & \multicolumn{3}{|c|}{$\begin{array}{c}\text { Economic production } \\
\text { volume No. of parts } \\
\text { (quantity) }\end{array}$} & \multirow{2}{*}{$\begin{array}{c}\text { Lead } \\
\text { time } \\
\text { (week } \\
\text { s) }\end{array}$} & \multicolumn{4}{|c|}{ Shape } \\
\hline & $\mathrm{L}$ & $\mathrm{M}$ & $\mathrm{H}$ & L & $\mathrm{M}$ & $\mathrm{H}$ & $\mathrm{L}$ & M & $\mathrm{H}$ & $\begin{array}{l}\text { Small } \\
\text { part } \\
\text { size }\end{array}$ & $\begin{array}{l}\text { Medium } \\
\text { part size }\end{array}$ & $\begin{array}{l}\text { Large } \\
\text { part } \\
\text { size }\end{array}$ & & $\begin{array}{l}3 \mathrm{D} \\
\text { solid } \\
\text { part }\end{array}$ & $\begin{array}{l}\text { 3D part } \\
\text { with } \\
\text { hollow } \\
\text { structure }\end{array}$ & $\begin{array}{l}\text { Circular } \\
\text { prismatic } \\
\text { structure }\end{array}$ & $\begin{array}{c}\text { Non- } \\
\text { circular } \\
\text { prismatic } \\
\text { structure }\end{array}$ \\
\hline Machining & & & $\sqrt{ }$ & & & $\sqrt{ }$ & & & $\sqrt{ }$ & $\leq 100$ & $\leq 100$ & $\leq 20$ & $8-12$ & $\sqrt{ }$ & & $\sqrt{ }$ & $\sqrt{ }$ \\
\hline $\begin{array}{l}\text { Injection } \\
\text { moulding }\end{array}$ & & & $\sqrt{ }$ & & & $\sqrt{ }$ & & & $\sqrt{ }$ & $\geq 100$ & $\geq 80$ & $\geq 50$ & $8-12$ & $\sqrt{ }$ & $\sqrt{ }$ & $\sqrt{ }$ & $\sqrt{ }$ \\
\hline $\begin{array}{l}\text { Vacuum } \\
\text { casting }\end{array}$ & & $\sqrt{ }$ & & 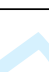 & $\sqrt{ }$ & & & & $\sqrt{ }$ & $\leq 100$ & $\leq 100$ & $\geq 25$ & $2-4$ & $\sqrt{ }$ & $\sqrt{ }$ & $\sqrt{ }$ & $\sqrt{ }$ \\
\hline Extrusion & $\sqrt{ }$ & & 8 & $\sqrt{ }$ & & & & & $\sqrt{ }$ & $\geq 50$ & $\geq 50$ & $\begin{array}{l}\geq 100 \\
\text { (Torre } \\
\text { Nieto, } \\
2010 \text { ) }\end{array}$ & $8-12$ & & & & $\sqrt{ }$ \\
\hline SLM & & $\sqrt{1}$ & $\sqrt{ }$ & & $\sqrt{ }$ & & \multicolumn{3}{|c|}{ Unknown } & $\leq 200$ & $\leq 50$ & $\leq 10$ & 4 & $\sqrt{ }$ & $\sqrt{ }$ & $\sqrt{ }$ & $\sqrt{ }$ \\
\hline FDM & $\sqrt{ }$ & $\sqrt{1}$ & & $\sqrt{ }$ & & 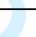 & 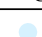 & $\sqrt{ }$ & & $\leq 100$ & $\leq 25$ & $\leq 10$ & 4 & $\sqrt{ }$ & $\sqrt{ }$ & $\sqrt{ }$ & $\sqrt{ }$ \\
\hline SLS & & $\sqrt{1}$ & $\sqrt{ }$ & & $\sqrt{ }$ & - & $\sqrt{ }$ & & & $\leq 100$ & $\leq 100$ & $\leq 10$ & 4 & $\sqrt{ }$ & $\sqrt{ }$ & $\sqrt{ }$ & $\sqrt{ }$ \\
\hline EBM & & $\sqrt{1}$ & & $\sqrt{ }$ & & & \multicolumn{3}{|c|}{$\frac{1}{\text { Unknown }}$} & $\leq 200$ & $\leq 25$ & $\leq 10$ & 4 & $\sqrt{ }$ & $\sqrt{ }$ & $\sqrt{ }$ & $\sqrt{ }$ \\
\hline SLA & & & $\sqrt{ }$ & & $\sqrt{ }$ & $\sqrt{ }$ & $\sqrt{ }$ & & & $\leq 100$ & $\leq 25$ & $\leq 10$ & 4 & $\sqrt{ }$ & $\sqrt{ }$ & $\sqrt{ }$ & $\sqrt{ }$ \\
\hline
\end{tabular}

Acronyms: Selective Laser Melting (SLM), Fused Deposition Modelling (FDM), Selective Laser Sintering (SLS), Electron Beam Melting (EBM), Stereolithography (SLA), Low (L), Medium (M) and High (H). If it is 'unknown', it is considered to be 'medium' in the initial screening.

N.B. An example for economic production volume No. of parts (quantity): for injection moulding to produce a small size of the part, the economical production volume would be greater than 100 units. If number of parts to be produced is lower than 100 units, injection moulding is not an economical production process.

\subsection{Technical evaluation and selection of feasible AM processes}

The initial screening stage has identified whether AM is potentially suitable based on the product requirements prior to the design process. Designers can now focus more on designing the product shapes to deliver the required functionalities and appearance. When the design process is progressing from conceptual to embodiment design, there will be a number of design iterations, by which the overall shape and structure of the product is determined. The surviving processes in the initial screening will be evaluated and selected, identifying an appropriate candidate, which will enable the designer to effectively develop the detailed design for the product.

\subsubsection{Multiple selection criteria for technical feasibility}

The technical feasibility selection criteria include available material, mechanical properties (including tensile strength, yield strength, flexural strength and elongation at break), part size, dimensional accuracy in millimetre, and multiple colours. A database of over 200 commercial AM systems from 15 internationally leading manufacturers has been constructed. The characteristics of these commercial systems are explained in Table 3. Part of the information in the AM database is shown Table 4. It is noted that, for simplicity, only one material is listed for each system shown in Table 4 and there are a wide range of materials stored in the database. 
Table 3: The collected characteristics of commercial AM systems (as-built)

\begin{tabular}{|c|c|c|}
\hline Technical characteristics & Unit & Description \\
\hline Technology type & $\mathrm{n} / \mathrm{a}$ & Type of technology e.g. SLS, SLM, SLA, FDM etc. \\
\hline Manufacturer & $\mathrm{n} / \mathrm{a}$ & Name of the AM machine manufacturer \\
\hline Machine model & $\mathrm{n} / \mathrm{a}$ & Name/model of the AM machine \\
\hline Available material & $\mathrm{n} / \mathrm{a}$ & Materials that are printable/processable by the specific AM machine \\
\hline Multiple colours & $\mathrm{n} / \mathrm{a}$ & Printer is able to build parts with multiple colours \\
\hline Build volume & $\mathrm{mm}^{3}$ & Maximum size of the part \\
\hline Layer thickness & $\mathrm{mm}$ & Minimum and maximum layer thickness \\
\hline Accuracy & $\mathrm{mm}$ & Minimum deviation between actual and nominal dimensions \\
\hline Surface roughness $(R a)$ & $\mu \mathrm{m}$ & $\begin{array}{l}\text { Deviations in the direction of the normal vector of a real surface of a printed } \\
\text { part from its ideal form }\end{array}$ \\
\hline Tensile strength & $\mathrm{MPa}$ & Capacity of a printed part to withstand loads tending to elongate \\
\hline Yield strength & $\mathrm{MPa}$ & Stress at which a printed part begins to deform plastically \\
\hline Flexural strength & $\mathrm{MPa}$ & Stress in a printed part just before it yields in a flexure test \\
\hline Elongation at break & $\%$ & $\begin{array}{l}\text { Ratio between changed length and initial length after breakage of the test } \\
\text { specimen }\end{array}$ \\
\hline
\end{tabular}


Table 4: Part of commercial AM machine information in the database

\begin{tabular}{|c|c|c|c|c|c|c|c|c|c|c|}
\hline Technology & Manufacturer & Model & $\begin{array}{l}\text { Build volume } \\
\qquad\left(\mathrm{mm}^{3}\right)\end{array}$ & $\begin{array}{l}\text { Layer thickness } \\
\text { (mm) }\end{array}$ & Material & $\begin{array}{c}\text { Dimensional } \\
\text { accuracy }(\mathrm{mm})\end{array}$ & $\begin{array}{c}\text { Tensile } \\
\text { strength } \\
(\mathrm{MPa})\end{array}$ & $\begin{array}{l}\text { Yield strength } \\
\text { (MPa) }\end{array}$ & $\begin{array}{c}\text { Flexural } \\
\text { strength } \\
(\mathrm{MPa})\end{array}$ & $\begin{array}{c}\text { Elongation at } \\
\text { break (\%) }\end{array}$ \\
\hline FDM & Stratasys & $\begin{array}{l}\text { Fortus } \\
450 \mathrm{c} \\
\end{array}$ & $406 \times 355 \times 406$ & $0.13-0.33$ & Polylactic Acid & 0.06 & 37 & $\mathrm{n} / \mathrm{a}$ & 62 & 4.4 \\
\hline $\begin{array}{l}\text { Metal FDM } \\
\text { /Material } \\
\text { extrusion }\end{array}$ & Markforged & Metal X & $300 \times 220 \times 180$ & $0.05-0.20$ & Fibre glass & 0.20 & 590 & $\mathrm{n} / \mathrm{a}$ & 210 & 3.8 \\
\hline SLS & EOS & P396 & $340 \times 340 \times 600$ & $0.06-0.18$ & $\begin{array}{l}\text { Polyamide } \\
\text { (PA2200) }\end{array}$ & 0.10 & 50 & $\mathrm{n} / \mathrm{a}$ & 52 & 20 \\
\hline SLS & 3D Systems & sP230 & $550 \times 550 \times 750$ & $0.08-0.15$ & $\begin{array}{l}\text { Polyamide } \\
\text { (DuraForm PA) }\end{array}$ & 0.10 & 43 & $\mathrm{n} / \mathrm{a}$ & 48 & 14 \\
\hline SLM & Renishaw & AM250 & $250 \times 250 \times 365$ & $0.02-0.10$ & Stainless steel 316L & 0.07 & $\begin{array}{l}607-678 \\
\end{array}$ & $480-550$ & $\mathrm{n} / \mathrm{a}$ & $27-45$ \\
\hline SLM & SLM Solutions & SLM 280 & $280 \times 280 \times 365$ & $0.02-0.075$ & Inconel 718 & 0.06 & 954-1034 & $637-767$ & $\mathrm{n} / \mathrm{a}$ & $23-25$ \\
\hline EBM & GE Arcam & A2X & $200 \times 200 \times 380$ & $0.05-0.15$ & Ti-6Al-4V & 0.20 & 1020 & 950 & $\mathrm{n} / \mathrm{a}$ & 14 \\
\hline MJP & 3D Systems & $\begin{array}{l}\text { Projet } \\
\text { 860Pro }\end{array}$ & $508 \times 381 \times 229$ & 0.10 & $\begin{array}{l}\text { VisiJet PXL } \\
\text { composite }\end{array}$ & 0.26 & 26.4 & $\mathrm{n} / \mathrm{a}$ & 44.1 & 0.21 \\
\hline
\end{tabular}

Acronyms: Fused Deposition Modelling (FDM), Selective Laser Sintering (SLS), Selective Laser Melting (SLM), Electron Beam Melting (EBM), Multijet Printing (MJP), n/a in here means the data is not published by the manufacturer. In the methodology, if the relevant data is $\mathrm{n} / \mathrm{a}$, it is considered to be adequate. 


\subsubsection{Analytic Hierarchy Process for ranking feasible AM processes and machines}

The evaluation and selection of AM processes are broken down into a hierarchy of criteria presented in Section 4.3.1. The characteristics of the AM processes are compared by taking each criterion alone. This enables designers and engineers to systematically analyse AM processes by comparing two criteria at a time, against each criterion (Armillotta, 2008, Majumder, 2015). Saaty's (2008) relative importance scale is employed to determine the weight (i.e. importance) of the criteria, as presented in Table 5. Each of the two criteria are compared at a time and the comparison result is in the form of a scale of criterion importance which is used to rank the AM processes.

Table 5: Relative scale of criterion importance adapted from Saaty (2008)

\begin{tabular}{lcc}
\hline Scale & Numeric assessment & Reciprocal \\
\hline Extremely preferred & 9 & $1 / 9$ \\
Very, very strong & 8 & $1 / 8$ \\
Very strong & 7 & $1 / 7$ \\
Strong plus & 6 & $1 / 6$ \\
Strong preferred & 5 & $1 / 5$ \\
Moderate plus & 4 & $1 / 4$ \\
Moderately preferred & 3 & $1 / 3$ \\
Weak plus & 2 & $1 / 2$ \\
Equally preferred & 1 & 1 \\
\hline
\end{tabular}

The relative importance for each criterion varies on a case-by-case basis, depending on the specific application. The designers/engineers will need to specify the importance level for each criterion. The comparative process performance for each selection criterion was analysed, resulting in a matrix that presents the comparison of the importance levels of the criteria, as shown in Table 6. Please note that the quality of the products/parts in the 'selection criterion' column is considered to be the average achievable quality claimed by the AM system manufacturers. It is also noted that, in this selection stage, the post-processing cost is not considered in comparison and ranking but it will be considered in the next selection stage detailed in Section 4.5 (production machine selection). The final ranking of each feasible AM processes is the sum of the product between the weights of the criteria and the weights of the alternative in the corresponding criteria. As of this selection stage, the AM processes that are technically capable of producing the designed product are identified with rankings. Generally, only a couple of processes are competent to fabricate the part but there might be a number of AM machines suitable for the production job. In the final selection stage presented in Section 4.5 , the production costs for each machine will be considered. 
Table 6: Assessment of comparative performance of commercial AM machines

\begin{tabular}{|c|c|c|c|c|c|c|}
\hline $\begin{array}{c}\text { Selection } \\
\text { criterion }\end{array}$ & FDM & SLM & SLS & MJP & EBM & HSS \\
\hline Accuracy & Average & Excellent & Excellent & Good & Low & Good \\
\hline Surface quality & Average & Good & Excellent & Excellent & Good & Excellent \\
\hline Tensile strength & Good & Excellent & Excellent & Good & Excellent & Good \\
\hline Yield strength & Good & Excellent & Excellent & Good & Excellent & Good \\
\hline Flexural strength & Excellent & Average & Excellent & Excellent & Average & Good \\
\hline $\begin{array}{c}\text { Elongation at } \\
\text { break }\end{array}$ & Excellent & Excellent & Excellent & Excellent & Excellent & Good \\
\hline Build volume & Good & Good & Good & Excellent & Excellent & Excellent \\
\hline
\end{tabular}

Acronyms: Fused Deposition Modelling (FDM), Selective Laser Melting (SLM), Selective Laser Sintering (SLS), Multijet Printing (MJP), Electron Beam Melting (EBM), High Speed Sintering (HSS)

\subsection{Re-evaluation of the feasible processes}

Upon identifying the AM processes that are technically capable of transforming the design (developed in the embodiment design and iterations) into a real part, the designer will need to choose one specific process to continue with the detail design stage. There are no strict rules in choosing the AM processes in this stage because the surviving processes identified in section 4.3 are all technically feasible based on the design that has been developed so far. The designer is suggested to develop the design based on the chosen process. For example, in a case where both SLS and FDM are feasible for the developed design, when SLS is chosen, the designer need to design necessary holes to get the unsintered powder out in the detail design stage. If FDM is chosen, support structures and removal need to be considered. DfM and/or DfAM principles need to be followed (Thompson et al., 2016). When the detail design is complete, all the technically feasible processes identified in section 4.3 will be re-evaluated based on the designed part using the machine database established in section 4.3.1. This step is to examine the manufacturability of the part and to identify features (which might have been designed in detail design and later design iteration stages) that would cause potential failure in production.

If unsuitable features are identified, the designer will need to make modifications to improve the manufacturability. A set of features that contains 27 features has been developed and included in the decision-making methodology. These features were designed to fit a design space of $50 \times 50 \times 75 \mathrm{~mm}^{3}$ and were scalable to fit different sizes of design space. They can be produced by certain AM processes with no manufacturability issues. Additional information including object build time, post-processing time, compressive strength and material usage is provided. The data was measured and tested in the experiments. It is noted that the development of the feature size was not to force the designers to use the features. Instead, it is to assist the designers in modifying the nonmanufacturable features by providing them with a reference. Some selected features for FDM are shown in Table 7. 
Table 7: Selected features in the feature set for design modification assistance

\begin{tabular}{|c|c|c|c|c|c|}
\hline Feature & $\begin{array}{l}\text { Object build } \\
\text { time (min) }\end{array}$ & $\begin{array}{l}\text { Post-processing } \\
\text { time (min) }\end{array}$ & $\begin{array}{c}\text { Compressive } \\
\text { strength } \\
\left(\mathrm{N} / \mathrm{mm}^{2}\right)\end{array}$ & $\begin{array}{l}\text { Material usage } \\
\qquad\left(\mathrm{mm}^{3}\right)\end{array}$ & Sample under test \\
\hline & 76 & 4 & 6.14 & 3670.50 & \\
\hline & 49 & 12 & 0.34 & 2166.49 & \\
\hline & 53 & 6 & 7.34 & 3820.74 & \\
\hline & 66 & 8 & 4.32 & 3935.34 & \\
\hline
\end{tabular}

\subsection{Production machine selection in terms of manufacturing costs}

As per the literature reviewed in Section 2, there have been a few cost models for production costs estimation. Fera et al.'s model (2017) is able to estimate manufacturing costs for a wide range of AM processes with relatively precise results. Therefore, it is chosen and adapted for estimating the manufacturing costs. The theoretical total costs for additively manufacturing a part are expressed in Equation 1:

Equation 1:

$$
C_{\text {tot.thoery }}=C_{\text {prep }}+C_{\text {build.job }}+C_{\text {setup }}+C_{\text {build }}+C_{\text {post }}
$$

where

$C_{\text {tot.thoery }}$ Total manufacturing costs in theoretical analysis [\$/part]

$C_{\text {prep }} \quad$ Cost for preparing geometry data e.g. support structures, orientation [\$/part]

$C_{\text {build.job }}$ Cost for build job assembly [\$/part]

$C_{\text {setup }} \quad$ Cost for machine set-up [\$/part]

$C_{\text {build }} \quad$ Cost for building up a part including material cost $[\$ /$ part $]$

$C_{\text {post }} \quad$ Cost for post-processing e.g. support material removal and bead blasting [\$/part]

In order to obtain a more precise estimation of actual manufacturing costs, five AM service bureaus were approached and the associated costs in actual printing were collected. Equation 2 was thus developed to calculate the actual total manufacturing costs. 


$$
\begin{aligned}
C_{\text {tot.actual }}= & C_{\text {tot.thoery }} \times \frac{100}{\alpha}+C_{\text {labour }}+C_{\text {energy }}+C_{m t} \\
& =C_{\text {tot.thoery }} \times \frac{100}{\alpha}+C_{\text {tot.theory }} \times \beta+C_{\text {tot.theory }} \times \gamma+C_{m t}
\end{aligned}
$$

where

$$
\begin{aligned}
& C_{\text {tot.actual }} \quad \text { Actual total manufacturing costs }[\$ / \text { part }] \\
& C_{\text {labour }} \quad \text { Labour cost }[\$ / \text { part }] \\
& C_{\text {energy }} \quad \text { Energy cost including Argon, compress air, temperature and moisture } \\
& \text { control and electricity [\$/part] } \\
& C_{m t} \quad \text { Machine maintenance cost, depending on technology, fixed [e.g. for SLS, } \\
& \$ 20 \mathrm{k} / \text { year i.e. } \$ 3.5 / \text { hour] } \\
& \text { a Print success rate [\%], depending on technology. For SLS, it is } 90 \% \text {, for } \\
& \text { SLM, it is } 95 \% \text {, for SLA is } 97 \% \text { in average } \\
& \beta \quad \text { The percentage of labour cost in theoretical total manufacturing costs [\%]. } \\
& \text { For SLS, it is } 10 \% \text {, for SLM, it is } 20 \% \text {, for SLA, it is } 20 \% \text { in average } \\
& \gamma \quad \text { The percentage of energy cost in theoretical total manufacturing costs }[\%] \text {. } \\
& \text { For SLS, it is } 10 \% \text {, for SLM, it is } 15 \% \text {, for SLA, it is } 5 \% \text { in average }
\end{aligned}
$$

The manufacturing costs for each technically feasible AM machines are estimated, which allows the designer to select the most appropriate process in terms of technical feasibility and economic viability.

\section{Case study and discussion}

\subsection{An industrial case study}

A real industrial case was studied, assessing the validity of the developed decision-making methodology. It was a component used in an exhaust gas duct for improving exhaust gas flow and reducing overheat temperatures in automotive industries. The duct consisted of four components as shown in Figure 7a, which were individually made and assembled. The component studied was highlighted in the red box in Figure 7a. The key requirements regarding this component specified by the client are listed below. This project required collaborative team effort including design engineers, designers and manufacturing engineers involved in both design and manufacture phases.

- The fundamental design requirements were good resistance to high temperature (up to $300^{\circ} \mathrm{C}$ ), internal structures that enabled good gas flow, lightweight if possible, medium tolerances $(0.10 \mathrm{~mm})$ for the region where the component was connected with another to allow proper assembly. Lead time was 12 weeks.

- As a pilot component to be installed onto a few vehicles, the production volume was only 20 units (i.e. 20 components in the red box in Figure 7a would be produced in total).

- This component was approximately $200 \mathrm{~mm}$ in length and approximately $80 \mathrm{~mm}$ in diameter. 


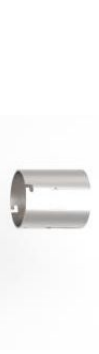

(a)

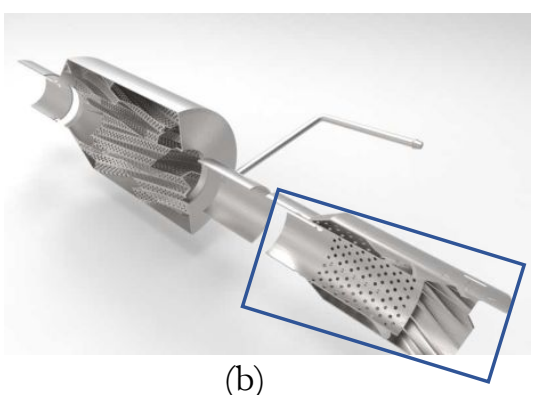

(b)

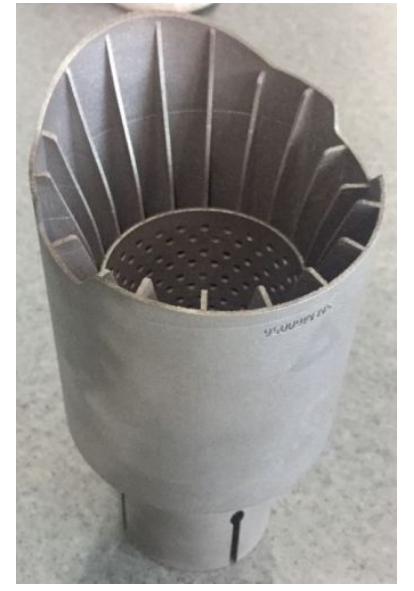

(c)

Figure 7: The exhaust gas duct (courtesy of Shinning 3D Ltd.) (a and b: CAD models, c: the real component manufactured by SLM)

\section{Initial screening}

Based on the above design specifications, there were both plastic and metallic materials that met the temperature requirements e.g. Aluminium Alloys (which can be machined, extruded or SLMed etc.) and Polyether ether ketone (PEEK, which can be machined, injection moulded and SLSed). Given that this component was considered as a large part, and production volume was only 20 units, from the economic production point of view, it can be identified from Table 2 that AM processes were economically viable. In addition, machining was another suitable candidate. From the technical point of view, prior to the design process, the engineers and designers had a conception, based on experience, that this component would be designed to have a cylindrical shape, which could be manufactured by AM.

(ii) Technical evaluation and selection of feasible manufacturing processes

Ashby's material selection method (Ashby et al., 2004, Ashby and Johnson, 2013) was used to select an appropriate material, which was finally determined to be the Titanium alloy Ti-6Al-4V. The engineers and designers then focused on designing the component to achieve the desired functionalities. After a few design iterations from conceptual to embodiment designs, the internal structure of the component was designed, which was close to the final structure shown in the blue box in Figure $7 \mathrm{~b}$. As the developed decision-making methodology was primarily for AM, visual examination was conducted by the engineers to determine the feasibility of machining the component, which was found not to be viable due to the cutting tool accessibility caused by the internal structures. Thus, the possible AM processes in terms of technical feasibility were evaluated by using the AHP technique. The selection criteria included material availability (i.e. whether a specific AM process is able to process Ti-6Al-4V in this case), tensile strength, part size (build volume), dimensional accuracy and multiple colour printability (this was to fit with different colours of car bodies). The importance scale defined for this case is listed in Table 8. Applying this scale of importance upon comparing 12 available AM processes, three of them (i.e. Material Extrusion, SLM and EBM in the order of preference) were identified to be technically 
capable to produce the component. By checking the AM machine database, there were 14 commercial systems (including 3D Systems DMP320 and DMP500, EOSINT M290 and M400, GE Arcam A2X, Renishaw AM250 and AM500, SLM Solutions SLM280 and SLM500, Aconity One, DMG Mori Lasertec 30 SLM, Mark.forged X3, X5 and X7) that were suitable for the identified three AM processes. It is noted that, as the component design had not been finalised at this stage, the AM process and machine to be used had not yet been decided. This step of process selection significantly narrowed down the manufacturing processes that were technically and economically viable for the intended design. It facilitated the designers to further improve the design for the potential AM process. As mentioned in sections 4.3 and 4.4, the designer was suggested to choose one process in mind but there was no strict requirement to choose the process in terms of the preference ranking generated from AHP. This was because all the identified three processes had met the technical and economic requirements. The final AM process would be determined after the design was fully developed in the next step.

Table 8: Importance scale for the component of the exhaust gas duct

\begin{tabular}{l|lllll|l}
\hline & $\begin{array}{l}\text { Material } \\
\text { availability }\end{array}$ & $\begin{array}{l}\text { Tensile } \\
\text { strength }\end{array}$ & Build volume & $\begin{array}{l}\text { Dimensional } \\
\text { accuracy }\end{array}$ & $\begin{array}{l}\text { Multiple colour } \\
\text { printability }\end{array}$ & $\begin{array}{l}\text { Criterion } \\
\text { weight }\end{array}$ \\
\hline Material availability & 1 & 9 & 6 & 9 & 9 & 0 \\
Tensile strength & $1 / 9$ & 1 & $1 / 3$ & 6 & 9 & 0.565 \\
Build volume & $1 / 6$ & 3 & 1 & 6 & 9 & 0.150 \\
Dimensional accuracy & $1 / 9$ & $1 / 6$ & $1 / 6$ & 1 & 3 & 0.205 \\
Multiple colour printability & $1 / 9$ & $1 / 9$ & $1 / 9$ & $1 / 3$ & 1 & 0.050 \\
Sum & 1.50 & 13.28 & 7.61 & 22.33 & 31.00 & 0.029 \\
\hline
\end{tabular}

(iii) Re-evaluation of the feasible manufacturing processes

Having completed the detail design, the feasible AM processes/machines were re-evaluated to identify any features that were out of the machine capability. For instance, some holes in Figure $7 \mathrm{~b}$ were smaller than the minimum diameter that could be printed by Markforged X series. As these holes were important to ensure gas flow and heat dissipation, which could not be changed or removed, the Markforged X series machines were ruled out.

(iv) Production machine selection in terms of manufacturing costs

The manufacturing costs for each technically feasible AM machine were calculated using Equation 2, and the results are shown in Table 9. By considering the selection results, SLM Solutions SLM280 was chosen to be the production machine for producing 20 off components in this project. 
Table 9: Estimation of manufacturing costs for the component of the exhaust gas duct

\begin{tabular}{ll}
\hline AM machine & $\begin{array}{l}\text { Estimated manufacturing cost } \\
\text { per part }(\$)\end{array}$ \\
\hline 3D Systems DMP320 & 343.77 \\
3D Systems DMP500 & 576.87 \\
EOSINT M290 & 317.14 \\
EOSINT M400 & 525.81 \\
GE Arcam A2X & 779.63 \\
Renishaw AM250 & 220.26 \\
Renishaw AM500 & 516.93 \\
SLM Solutions SLM280 & 277.33 \\
SLM Solutions SLM500 & 540.25 \\
Aconity One & 490.62 \\
DMG Mori Lasertec 30 SLM & 313.87 \\
\hline
\end{tabular}

\subsection{Discussion}

The above case study has demonstrated the capability of the developed decision-making methodology in identifying appropriate AM process and machine for production, as well as assisting the design evolution of the exhaust gas duct. The methodology has overcome the main limitations of the current decision-making models that only identify the AM process based on a finished design with limited support to facilitate the designer to design the part, as depicted in Figure 1.

The methodology consists of four major elements including initial screening, technical evaluation and selection of feasible AM processes, re-evaluation of the feasible processes, and production machine selection in terms of manufacturing costs. The four elements are used in (1) early design stages or prior to the design process, (2) embodiment design, (3) detail design and (4) design finalisation, respectively, in sequence. The methodology aims to assist designers and engineers to efficiently identify the technically feasible processes in early design stages. This enables them to focus more on developing the required product functionalities and appearance with the feasible processes in mind, utilising the process characteristics more effectively. After the detail design is finished, the feasible processes identified in the previous steps will be re-evaluated, which re-assesses their technical feasibility for manufacturing the designed product e.g. overhanging structures, minimum feature sizes and achievable tolerances. The design can also be modified accordingly if needed to ensure the manufacturability of the designed product. A pilot feature set with some selected features shown in Table 7 was developed to provide the designers with a reference, helping them modify the design. The factors considered in developing the feature set included object build time, post-processing time, material usage and the resulting compressive strength. It is noted that this feature set by no means covers all factors that need to be considered during the design process. For example, a design that can be produced by either FDM or SLS may require additional considerations if it is eventually decided to be built by FDM such as support structure, the resulting extra time in post-processing and the surface quality affected by the support (Jiang et al., 2019a). It is worth mentioning that, the feature set will continue to be developed into a series of groups that provide specific functionalities. For example, a group will consist of features that provide enhanced mechanical properties, and another group will be comprised of features that can be built 
with a minimal build time or post-processing requirements. This will allow designers to choose appropriate features to assist the design modification. Upon finishing the design, the manufacturing costs for commercial production machines will be estimated, by which the most appropriate AM production machine in terms of technical feasibility and economic viability is identified. However, it should also be noted that process planning is not taken into account in production machine selection. It is well known that an optimised process plan, e.g. laser scan strategies in SLM/SLS and deposition tool path strategies in FDM (Jiang et al., 2019b, Zhu et al., 2013) can have a significant impact on build time, mechanical properties and surface finish. In order to expand the decisionmaking methodology and make it applicable to traditional manufacturing processes, more aspects need to be considered, for instance, the life cycle and environmental impact (Chiu and Lin, 2016). Additively manufactured parts can sometimes be less cost effective but the reduced material consumption and the enhanced functionality can be an advantage for the environment and the product life cycle.

In addition to the above, the proposed decision-making methodology has other limitations. It is assumed the part/product is to be manufactured in one material. It cannot deal with multi-material components. Having said that, building multi-material parts is currently one of the main challenges for AM technologies. Another factor that has not been considered thoroughly during the development of the methodology was the database update. It would be worth investigating the possibility of integrating the methodology into the 'cloud' under the Industry 4.0 context that allows for prompt feedback and update.

Despite the fact that it is virtually impossible to include all aspects involved in design and manufacture, the methodology has shown the capability to identify appropriate AM processes in different design stages in terms of process capability, economic production and manufacturing costs. As compared to the existing AM process selection methods reported in the literature where the selection takes place after the part is designed, the developed methodology facilitates the designer to create a more sensible design in the design process, addressing the process characteristics and limitations in the early design stages. This has an implication to significantly enhance design efficiency and reduce production costs.

\section{Conclusions and future work}

In this study, a decision-making methodology that can seamlessly be integrated into product/part design for AM process selection has been developed. It enables designers to (i) identify whether AM is an economically and technically viable production method based on the initial product design requirements, (ii) design and modify the part for AM, and (iii) select the final AM process and machine for volume production. The industrial case study of a real component of exhaust gas duct has demonstrated the efficacy of the methodology in facilitating the part design and identifying the appropriate process and machine.

To achieve the claimed benefits, the methodology was developed into four key elements, namely initial screening, technical evaluation and selection of feasible AM processes, re-evaluation of the feasible processes, and 


\section{References:}

ADHIKARI, P. R. \& MIRSHAMS, R. 2017. Study of Knowledge-Based System (KBS) and Decision Making Methodologies in Materials Selection for Lightweight Aircraft Metallic Structures. Journal of Applied Science \& Engineering Technology, 5, 1.

ARMILLOTTA, A. 2008. Selection of layered manufacturing techniques by an adaptive AHP decision model. Robotics and Computer-Integrated Manufacturing, 24, 450-461.

ASHBY, M. F., BRÉCHET, Y. J. M., CEBON, D. \& SALVO, L. 2004. Selection strategies for materials and processes. Materials \& Design, 25, 51-67.

ASHBY, M. F. \& JOHNSON, K. 2013. Materials and design: the art and science of material selection in product design, Oxford, UK, Butterworth-Heinemann.

ATZENI, E. \& SALMI, A. 2012. Economics of additive manufacturing for end-usable metal parts. The International Journal of Advanced Manufacturing Technology, 62, 1147-1155.

BALDINGER, M., LEVY, G., SCHÖNSLEBEN, P. \& WANDFLUH, M. 2016. Additive manufacturing cost estimation for buy scenarios. Rapid Prototyping Journal, 22, 871-877.

BAUMERS, M., BELTRAMETTI, L., GASPARRE, A. \& HAGUE, R. 2017. Informing additive manufacturing technology adoption: total cost and the impact of capacity utilisation. International Journal of Production Research, 55, 6957-6970.

BOOTHROYD, G., DEWHURST, P. \& KNIGHT, W. 2002. Product design for manufacture and assembly. 2nd ed.: CRC Press, New York.

CHAKLADAR, N. D. \& CHAKRABORTY, S. 2008. A combined TOPSIS-AHP-method-based approach for non-traditional machining processes selection. Proceedings of the Institution of Mechanical Engineers, Part B: Journal of Engineering Manufacture, 222, 1613-1623. 
CHIU, M.-C. \& LIN, Y.-H. 2016. Simulation based method considering design for additive manufacturing and supply chain: An empirical study of lamp industry. Industrial Management \& Data Systems, 116, 322-348.

EASTERBY-SMITH, M., THORPE, R. \& JACKSON, P. 2012. Management Research, SAGE Publications Ltd., London.

FAVI, C., GERMANI, M. \& MANDOLINI, M. 2018. Development of complex products and production strategies using a multi-objective conceptual design approach. The International Journal of Advanced Manufacturing Technology, 95, 1281-1291.

FERA, M., FrugGiero, F., COSTABILE, G., LAMBIASE, A. \& PHAM, D. T. 2017. A new mixed production cost allocation model for additive manufacturing (MiProCAMAM). The International Journal of Advanced Manufacturing Technology, 92, 4275-4291.

HASSAN, A., SIADAT, A., DANTAN, J.-Y. \& MARTIN, P. 2010. Conceptual process planning - an improvement approach using QFD, FMEA, and ABC methods. Robotics and Computer-Integrated Manufacturing, 26, 392-401.

HE, B., LUO, T. \& HUANG, S. 2019. Product sustainability assessment for product life cycle. Journal of Cleaner Production, 206, 238-250.

JIANG, J., LOU, J. \& HU, G. 2019a. Effect of support on printed properties in fused deposition modelling processes. Virtual and Physical Prototyping, 1-8.

JIANG, J., STRINGER, J. \& XU, X. 2017. Support Optimization for Flat Features via Path Planning in Additive Manufacturing. 3D Printing and Additive Manufacturing, 6, 171-179.

JIANG, J., XU, X. \& STRINGER, J. 2019b. Optimization of process planning for reducing material waste in extrusion based additive manufacturing. Robotics and Computer-Integrated Manufacturing, 59, 317-325.

JUSTINO NETTO, J. M., RAGONI, I. G., FREZZATTO SANTOS, L. E. \& SILVEIRA, Z. C. 2019. Selecting low-cost 3D printers using the AHP method: a case study. SN Applied Sciences, 1, 335.

KAMBLE, S. S., GUNASEKARAN, A. \& GAWANKAR, S. A. 2018. Sustainable Industry 4.0 framework: A systematic literature review identifying the current trends and future perspectives. Process Safety and Environmental Protection, 117, 408-425.

KAMPS, T., LUTTER-GUENTHER, M., SEIDEL, C., GUTOWSKI, T. \& REINHART, G. 2018. Cost- and energy-efficient manufacture of gears by laser beam melting. CIRP Journal of Manufacturing Science and Technology, 21, 47-60.

KHAJAVI, S. H., DENG, G., HOLMSTRÖM, J., PUUKKO, P. \& PARTANEN, J. 2018. Selective laser melting raw material commoditization: impact on comparative competitiveness of additive manufacturing. International Journal of Production Research, 1-23.

KHALEEQ UZ ZAMAN, U., SIADAT, A., RIVETTE, M., BAQAI, A. A. \& QIAO, L. 2017. Integrated product-process design to suggest appropriate manufacturing technology: a review. The International Journal of Advanced Manufacturing Technology, 91, 1409-1430.

KIM, G. \& OH, Y. 2008. A benchmark study on rapid prototyping processes and machines: quantitative comparisons of mechanical properties, accuracy, roughness, speed, and material cost. Proceedings of the Institution of Mechanical Engineers, Part B: Journal of Engineering Manufacture, 222, 201-215.

KOPF, R., GOT'TWALD, J., JACOB, A., BRANDT, M. \& LANZA, G. 2018. Cost-oriented planning of equipment for selective laser melting (SLM) in production lines. CIRP Annals, in press. 
KRETZSCHMAR, N., ITUARTE, I. F. \& PARTANEN, J. 2018. A decision support system for the validation of metal powder bed-based additive manufacturing applications. The International Journal of Advanced Manufacturing Technology, 96, 3679-3690.

L., R., A., S. \& K., W. 2013. An integrated cost-model for selective laser melting (SLM). Rapid Prototyping Journal, 19, 208-214.

LOUISE BARRIBALL, K. \& WHILE, A. 1994. Collecting Data using a semi-structured interview: a discussion paper. Journal of advanced nursing, 19, 328-335.

LU, Y. 2017. Industry 4.0: A survey on technologies, applications and open research issues. Journal of Industrial Information Integration, 6, 1-10.

LUKIC, D., MILOSEVIC, M., ANTIC, A., BOROJEVIC, S. \& FICKO, M. 2017. Multi-criteria selection of manufacturing processes in the conceptual process planning. Advances in Production Engineering \& Management, 12, 151-162.

MAJUMDER, M. 2015. Multi Criteria Decision Making. Impact of Urbanization on Water Shortage in Face of Climatic Aberrations. Singapore: Springer Singapore.

MANÇANARES, C. G., DE S. ZANCUL, E., CAVALCANTE DA SILVA, J. \& CAUCHICK MIGUEL, P. A. 2015. Additive manufacturing process selection based on parts' selection criteria. The International Journal of Advanced Manufacturing Technology, 80, 1007-1014.

MARDANI, A., JUSOH, A., MD NOR, K., KHALIFAH, Z., ZAKWAN, N. \& VALIPOUR, A. 2015. Multiple criteria decision-making techniques and their applications-a review of the literature from 2000 to 2014 Economic Research-Ekonomska Istrą̌ivanja, 28, 516-571.

MU, E. \& PEREYRA-ROJAS, M. 2017. Understanding the Analytic Hierarchy Process. Practical Decision Making: An Introduction to the Analytic Hierarchy Process (AHP) Using Super Decisions V2. Cham: Springer International Publishing.

NDIP-AGBOR, E., CAO, J. \& EHMANN, K. 2018. Towards smart manufacturing process selection in CyberPhysical Systems. Manufacturing Letters, 17, 1-5.

SAATY, T. L. 2008. Decision making with the analytic hierarchy process. International Journal of Services Sciences, 1 , 83-98.

SCHMIDT, M., MERKLEIN, M., BOURELL, D., DIMITROV, D., HAUSOTTE, T., WEGENER, K., OVERMEYER, L., VOLLERTSEN, F. \& LEVY, G. N. 2017. Laser based additive manufacturing in industry and academia. CIRP Annals, 66, 561-583.

THOMPSON, M. K., MORONI, G., VANEKER, T., FADEL, G., CAMPBELL, R. I., GIBSON, I., BERNARD, A., SCHULZ, J., GRAF, P. \& AHUJA, B. 2016. Design for Additive Manufacturing: Trends, opportunities, considerations, and constraints. CIRP Annals-Manufacturing Technology, 65, 737-760.

TORRE NIETO, J. 2010. Feature based costing of extruded parts. Masters of Science, University of Illinois at UrbanaChampaign,.

WANG, Y., ZHONG, R. Y. \& XU, X. 2018. A decision support system for additive manufacturing process selection using a hybrid multiple criteria decision-making method. Rapid Prototyping Journal, 24, 1544-1553.

WRIGHT, I. C. 1998. Design methods in engineering and product design, McGraw-Hill London. 
YIM, S. \& ROSEN, D. Build time and cost models for additive manufacturing process selection. ASME 2012 International Design Engineering Technical Conferences and Computers and Information in Engineering Conference, August 12-15, 20122012 Chicago, Illinois, USA. American Society of Mechanical Engineers, 375-382.

ZAMAN, U. K. U., RIVETTE, M., SIADAT, A. \& MOUSAVI, S. M. 2018. Integrated product-process design: Material and manufacturing process selection for additive manufacturing using multi-criteria decision making. Robotics and Computer-Integrated Manufacturing, 51, 169-180.

ZHA, X. F. 2005. A web-based advisory system for process and material selection in concurrent product design for a manufacturing environment. The International Journal of Advanced Manufacturing Technology, 25, 233-243.

ZHANG, Y., XU, Y. \& BERNARD, A. 2014. A new decision support method for the selection of RP process: knowledge value measuring. International Journal of Computer Integrated Manufacturing, 27, 747-758.

ZHU, Z., DHOKIA, V. \& NEWMAN, S. T. 2016. A new algorithm for build time estimation for fused filament fabrication technologies. Proceedings of the Institution of Mechanical Engineers, Part B: Journal of Engineering Manufacture, 230, 2214-2228.

ZHU, Z., DHOKIA, V. \& NEWMAN, S. T. 2017. A novel decision-making logic for hybrid manufacture of prismatic components based on existing parts. Journal of Intelligent Manufacturing, 28, 131-148.

ZHU, Z., DHOKIA, V. G. \& NEWMAN, S. T. 2013. The development of a novel process planning algorithm for an unconstrained hybrid manufacturing process. Journal of Manufacturing Processes, 15, 404-413. 


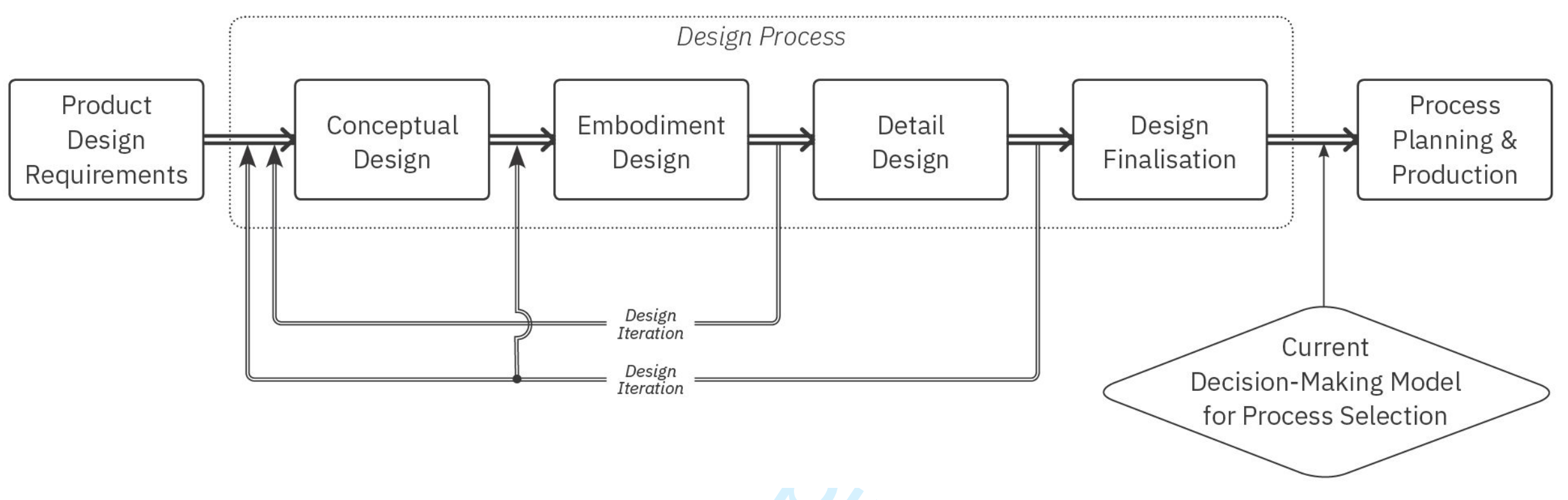

Figure 1: The typical process of design, process selection decision-making and manufacture adapted from (Wright, 1998, Khaleeq uz Zaman et al., 2017) 


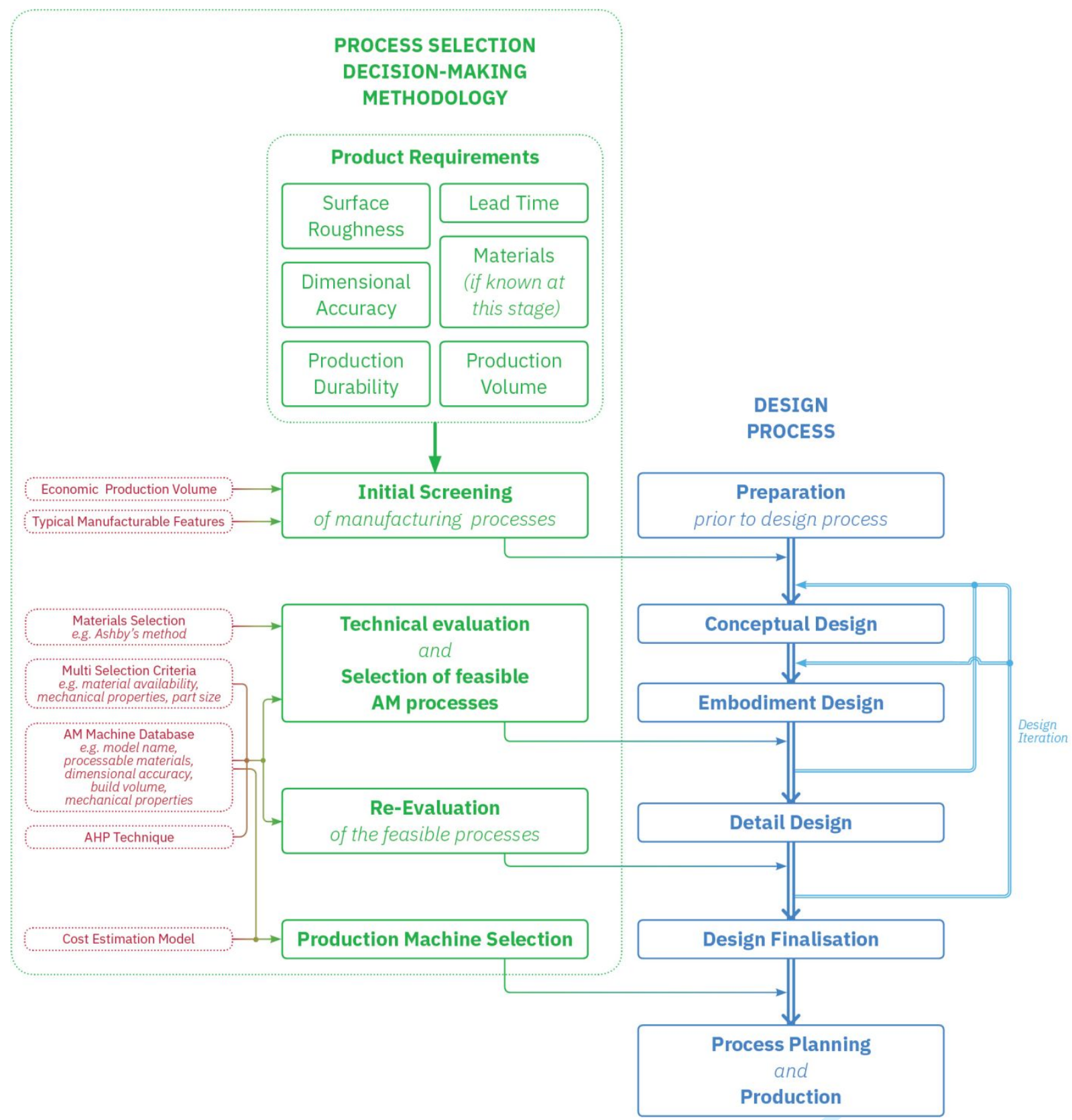

Figure 2: The developed decision-making methodology 


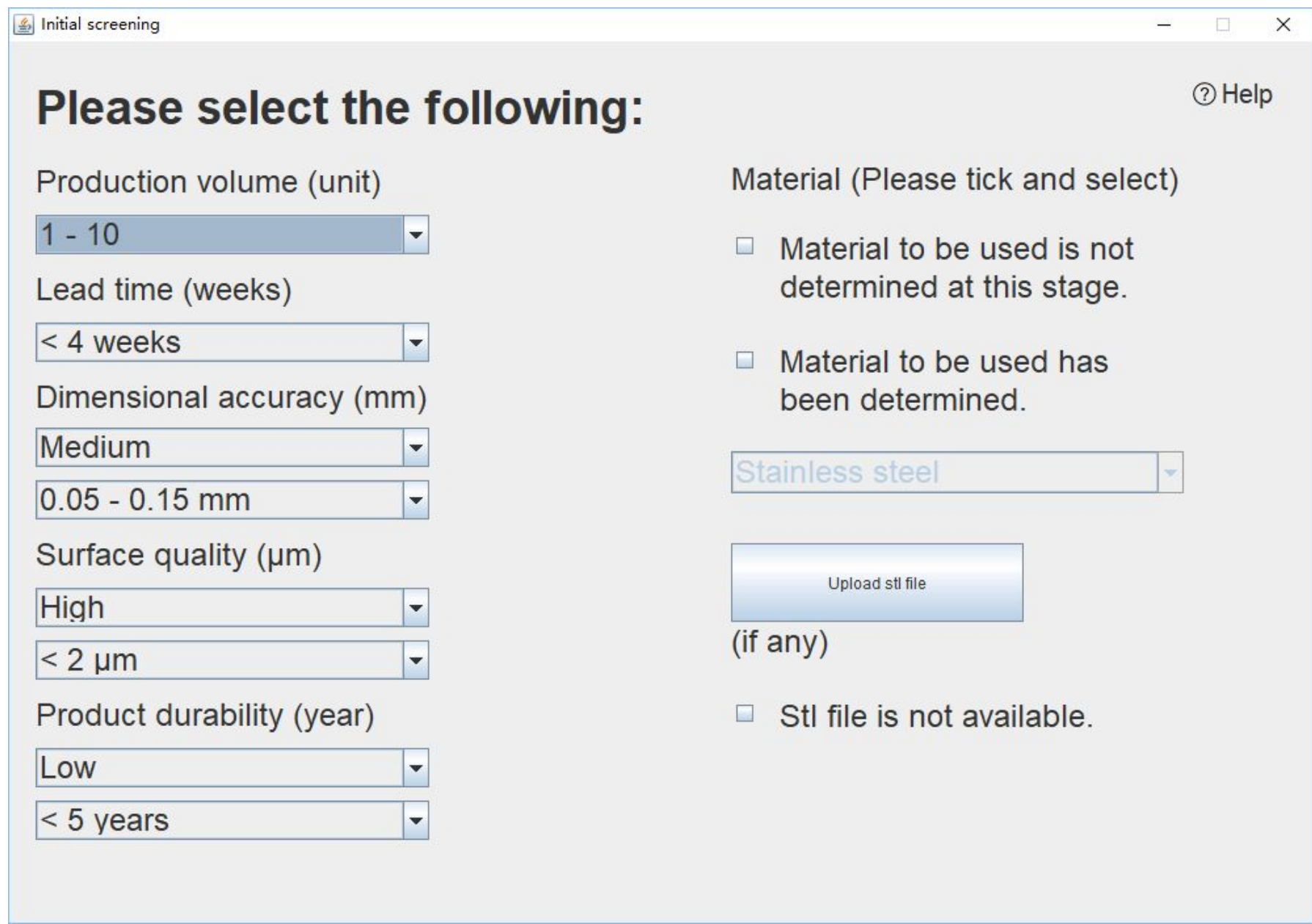

Figure 3: The input parameters for initial screening 


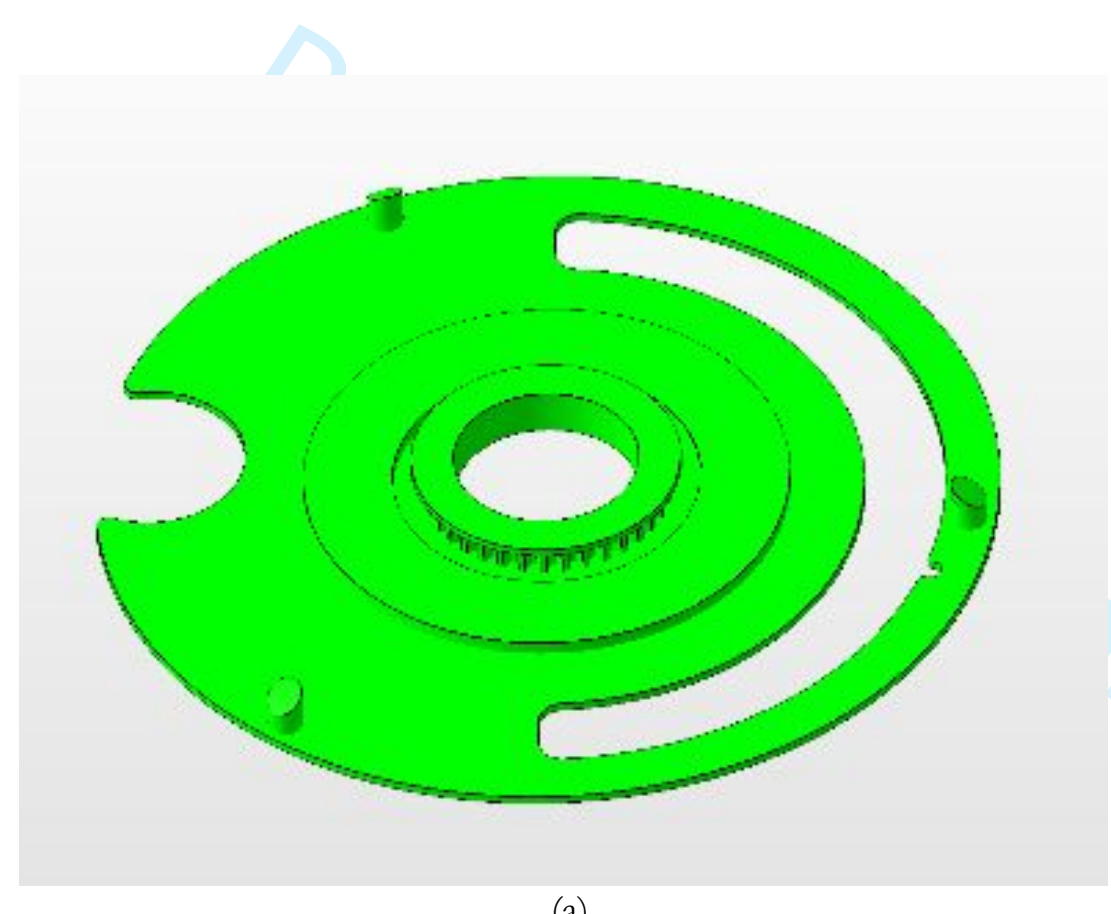

(a)

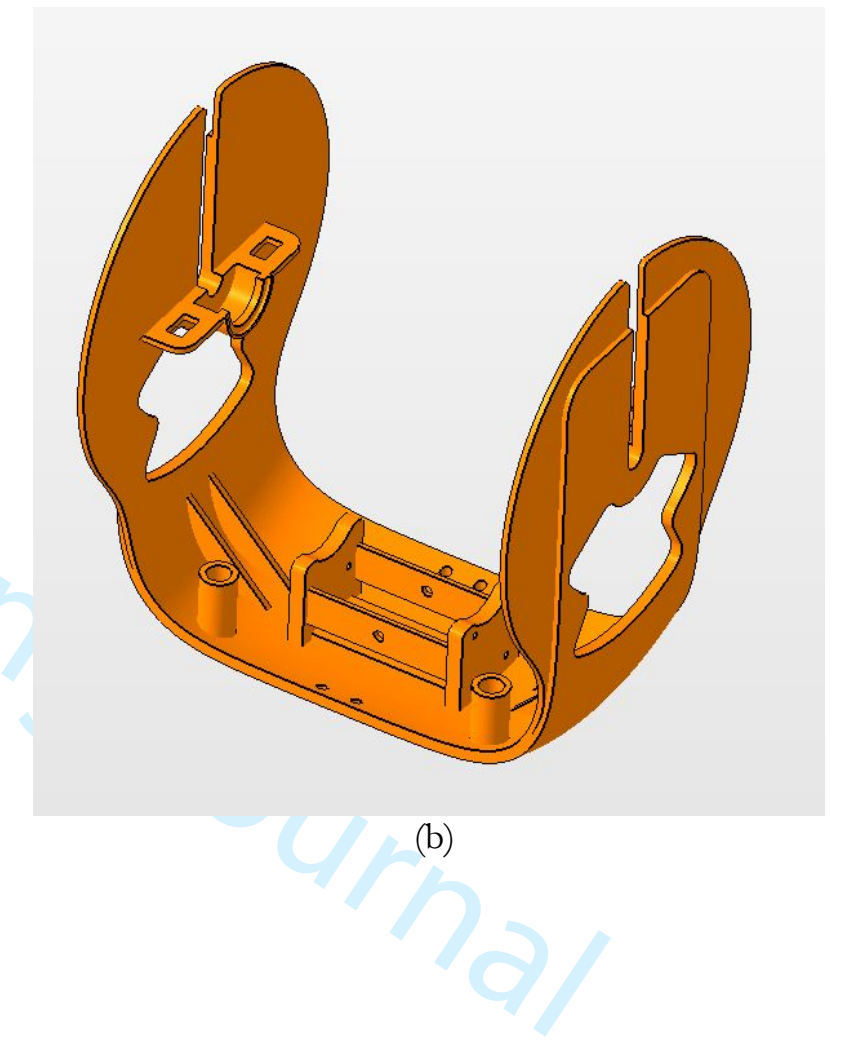

Figure 4: Two example parts used for identifying economic production volume for AM 


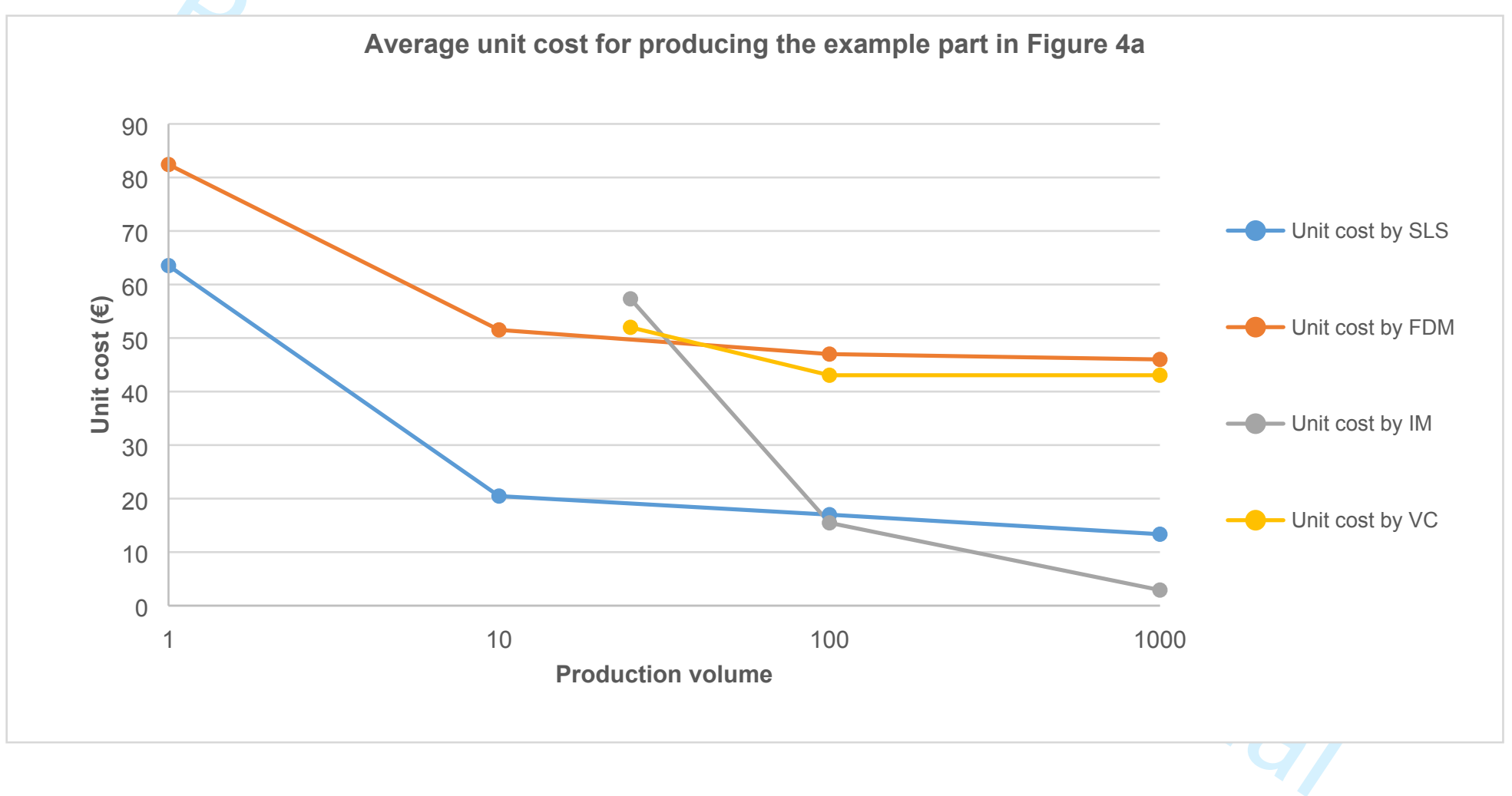

Figure 5: The average unit cost for producing the example part in

Figure $4 \mathrm{a}$ 


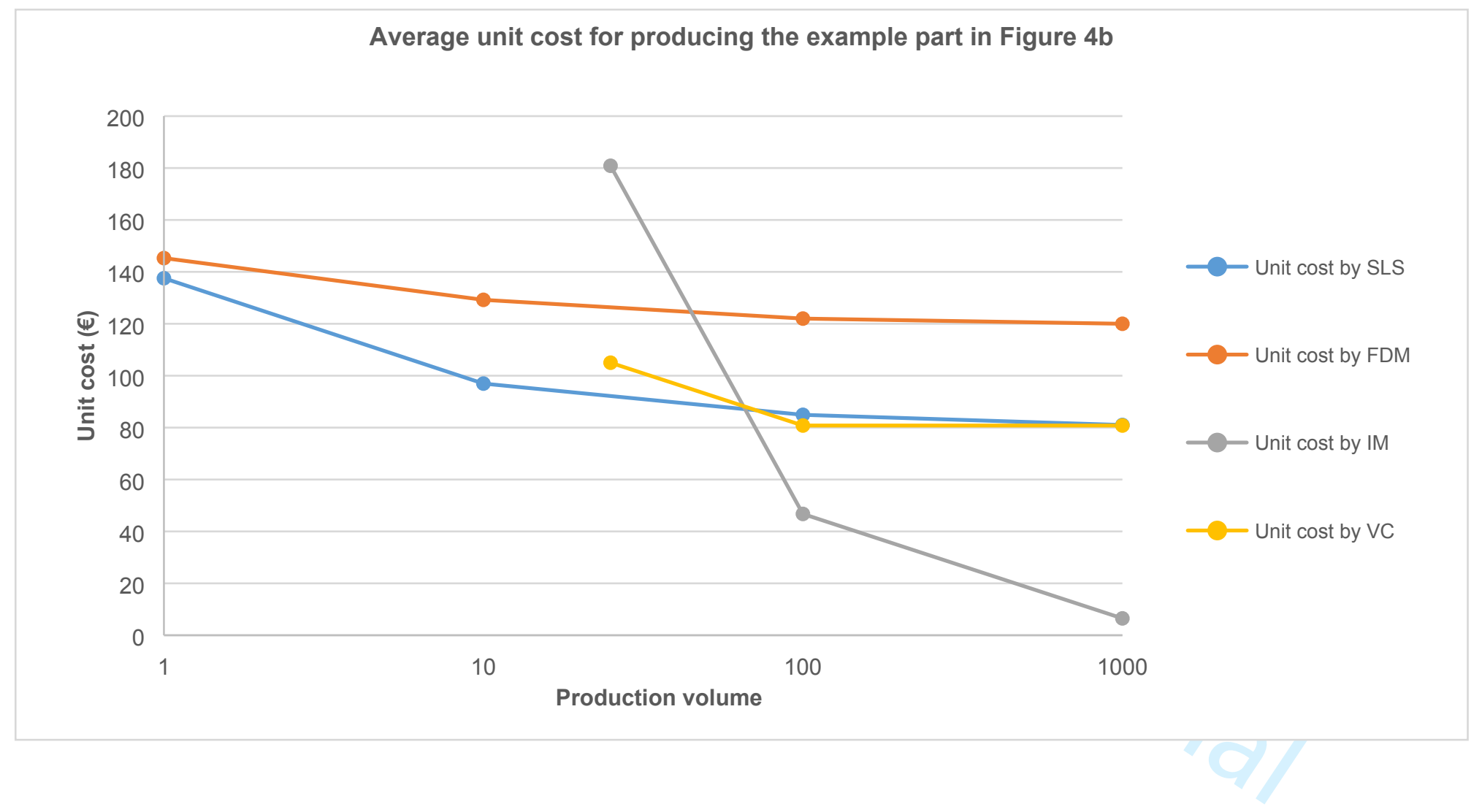

Figure 6: The average unit cost for producing the example part in

Figure 4b 


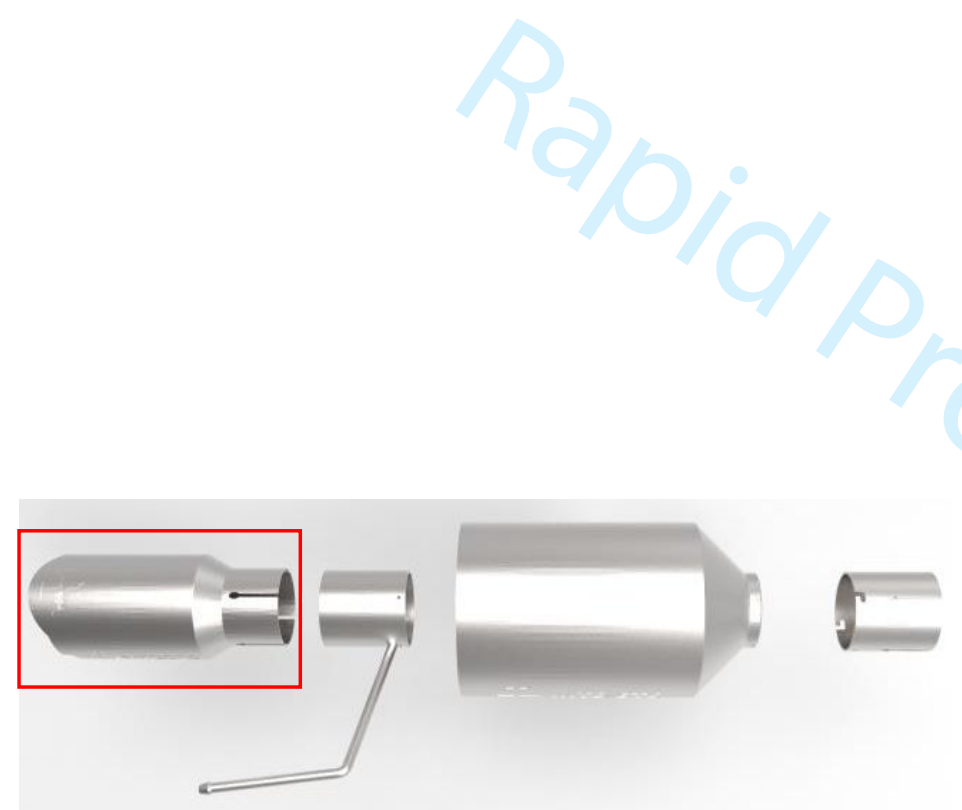

(a)
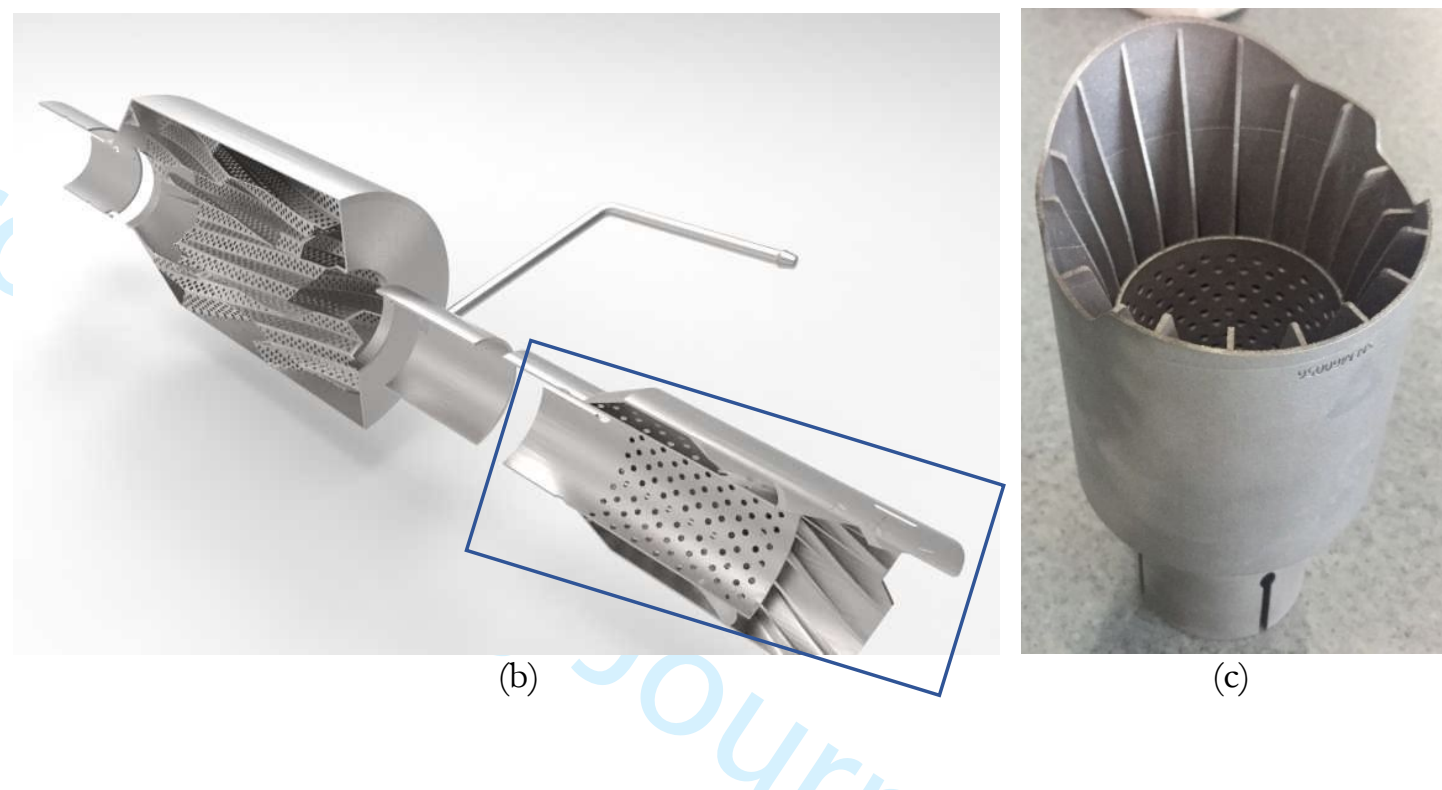

(c)

Figure 7: The exhaust gas duct (courtesy of Shinning 3D Ltd.) (a and b: CAD models, c: the real component manufactured by SLM) 
Table 1: Summary of levels of selection criteria in initial screening

\begin{tabular}{|l|l|l|l|}
\hline \multicolumn{1}{|c|}{ Selection criteria } & \multicolumn{2}{c|}{ Level } \\
\cline { 2 - 4 } & \multicolumn{1}{c|}{ High } & \multicolumn{1}{c|}{ Medium } & $>0.15 \mathrm{~mm}$ \\
\hline Dimensional accuracy & $<0.05 \mathrm{~mm}$ & $0.05-0.15 \mathrm{~mm}$ & $>8 \mu \mathrm{m}$ \\
\hline Surface quality $(\mathrm{Ra})$ & $<2 \mu \mathrm{m}$ & $2-8 \mu \mathrm{m}$ & $<5$ years \\
\hline Durability & $10+$ years & $5-10$ years & \\
\hline
\end{tabular}

25

26

2

28

29

30

31

32

33

34

35

36

37

38

39

40

4

4 
Table 2: Part of the selection matrix for initial screening of manufacturing processes

\begin{tabular}{|c|c|c|c|c|c|c|c|c|c|c|c|c|c|c|c|c|c|}
\hline \multirow{2}{*}{ Process } & \multicolumn{3}{|c|}{$\begin{array}{l}\text { Dimensional } \\
\text { accuracy }\end{array}$} & \multicolumn{3}{|c|}{ Surface quality } & \multicolumn{3}{|c|}{$\begin{array}{l}\text { Product } \\
\text { durability }\end{array}$} & \multicolumn{3}{|c|}{$\begin{array}{l}\text { Economic production volume No. of } \\
\text { parts (quantity) }\end{array}$} & \multirow{2}{*}{$\begin{array}{l}\text { Lead time } \\
\text { (weeks) }\end{array}$} & \multicolumn{4}{|c|}{ Shape } \\
\hline & $\mathrm{L}$ & M & $\mathrm{H}$ & $\mathrm{L}$ & M & $\mathrm{H}$ & $\mathrm{L}$ & M & $\mathrm{H}$ & $\begin{array}{l}\text { Small } \\
\text { part size }\end{array}$ & $\underset{\text { size }}{\text { Medium part }}$ & $\begin{array}{l}\text { Large part } \\
\text { size }\end{array}$ & & $\begin{array}{l}\text { 3D solid } \\
\text { part }\end{array}$ & $\begin{array}{c}\text { 3D part with } \\
\text { hollow structure }\end{array}$ & $\begin{array}{l}\text { Circular } \\
\text { prismatic } \\
\text { structure }\end{array}$ & $\begin{array}{c}\text { Non-circular } \\
\text { prismatic } \\
\text { structure }\end{array}$ \\
\hline Machining & & & $\sqrt{ }$ & & & $\sqrt{ }$ & & & $\sqrt{ }$ & $\leq 100$ & $\leq 100$ & $\leq 20$ & $8-12$ & $\sqrt{ }$ & & $\sqrt{ }$ & $\sqrt{ }$ \\
\hline Injection moulding & & & $\sqrt{ }$ & & & $\sqrt{ }$ & & & $\sqrt{ }$ & $\geq 100$ & $\geq 80$ & $\geq 50$ & $8-12$ & $\sqrt{ }$ & $\sqrt{ }$ & $\sqrt{ }$ & $\sqrt{ }$ \\
\hline Vacuum casting & & $\sqrt{ }$ & & & $\sqrt{ }$ & & & & $\sqrt{ }$ & $\leq 100$ & $\leq 100$ & $\geq 25$ & $2-4$ & $\sqrt{ }$ & $\sqrt{ }$ & $\sqrt{ }$ & $\sqrt{ }$ \\
\hline Extrusion & $\sqrt{ }$ & & & $\sqrt{ }$ & & & & & $\sqrt{ }$ & $\geq 50$ & $\geq 50$ & $\begin{array}{l}\geq 100 \\
\text { (Torre } \\
\text { Nieto, } \\
2010 \text { ) }\end{array}$ & $8-12$ & & & & $\sqrt{ }$ \\
\hline SLM & & $\sqrt{ }$ & $\sqrt{ }$ & & $\sqrt{ }$ & & \multicolumn{3}{|c|}{ Unknown } & $\leq 200$ & $\leq 50$ & $\leq 10$ & 4 & $\sqrt{ }$ & $\sqrt{ }$ & $\sqrt{ }$ & $\sqrt{ }$ \\
\hline FDM & $\sqrt{ }$ & $\sqrt{ }$ & & $\sqrt{ }$ & & & & $\sqrt{ }$ & & $\leq 100$ & $\leq 25$ & $\leq 10$ & 4 & $\sqrt{ }$ & $\sqrt{ }$ & $\sqrt{ }$ & $\sqrt{ }$ \\
\hline SLS & & $\sqrt{ }$ & $\sqrt{ }$ & & $\sqrt{ }$ & & $\sqrt{ }$ & & & $\leq 100$ & $\leq 100$ & $\leq 10$ & 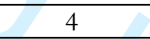 & $\sqrt{ }$ & $\sqrt{ }$ & $\sqrt{ }$ & $\sqrt{ }$ \\
\hline EBM & & $\sqrt{ }$ & & $\sqrt{ }$ & & & \multicolumn{3}{|c|}{ Unknown } & $\leq 200$ & $\leq 25$ & $\leq 10$ & 4 & $\sqrt{ }$ & $\sqrt{ }$ & $\sqrt{ }$ & $\sqrt{ }$ \\
\hline SLA & & & $\sqrt{ }$ & & $\sqrt{ }$ & $\sqrt{ }$ & $\sqrt{ }$ & & & $\leq 100$ & $\leq 25$ & $\leq 10$ & 4 & $\sqrt{ }$ & $\sqrt{ }$ & $\sqrt{ }$ & $\sqrt{ }$ \\
\hline
\end{tabular}

Acronyms: Selective Laser Melting (SLM), Fused Deposition Modelling (FDM), Selective Laser Sintering (SLS), Electron Beam Melting (EBM), Stereolithography (SLA), Low (L), Medium (M) and High $(\mathrm{H})$. If it is 'unknown', it is considered to be 'medium' in the initial screening.

N.B. An example for economic production volume No. of parts (quantity): for injection moulding to produce a small size of the part, the economical production volume would be greater than 100 units. If number of parts to be produced is lower than 100 units, injection moulding is not an economical production process. 
Table 3: The collected characteristics of commercial AM systems (as-built)

\begin{tabular}{l|l|l}
\hline Technical characteristics & Unit & Description \\
\hline Technology type & $\mathrm{n} / \mathrm{a}$ & Type of technology e.g. SLS, SLM, SLA, FDM etc. \\
Manufacturer & $\mathrm{n} / \mathrm{a}$ & Name of the AM machine manufacturer \\
Machine model & $\mathrm{n} / \mathrm{a}$ & Name/model of the AM machine \\
Available material & $\mathrm{n} / \mathrm{a}$ & Materials that are printable/processable by the specific AM machine \\
Multiple colours & $\mathrm{n} / \mathrm{a}$ & Printer is able to build parts with multiple colours \\
Build volume & $\mathrm{mm}^{3}$ & Maximum size of the part \\
Layer thickness & $\mathrm{mm}$ & Minimum and maximum layer thickness \\
Accuracy & $\mathrm{mm}$ & Minimum deviation between actual and nominal dimensions \\
Surface roughness (Ra) & $\mu \mathrm{m}$ & Deviations in the direction of the normal vector of a real surface of a printed \\
& part from its ideal form \\
Tensile strength & $\mathrm{MPa}$ & Capacity of a printed part to withstand loads tending to elongate \\
Yield strength & $\mathrm{MPa}$ & Stress at which a printed part begins to deform plastically \\
Flexural strength & $\mathrm{MPa}$ & Stress in a printed part just before it yields in a flexure test \\
Elongation at break & $\%$ & Ratio between changed length and initial length after breakage of the test \\
\end{tabular}


Table 4: Part of commercial AM machine information in the database

\begin{tabular}{|c|c|c|c|c|c|c|c|c|c|c|}
\hline Technology & Manufacturer & Model & $\begin{array}{l}\text { Build volume } \\
\qquad\left(\mathrm{mm}^{3}\right)\end{array}$ & $\begin{array}{l}\text { Layer thickness } \\
(\mathrm{mm})\end{array}$ & Material & $\begin{array}{c}\text { Dimensional } \\
\text { accuracy }(\mathrm{mm})\end{array}$ & $\begin{array}{l}\text { Tensile } \\
\text { strength } \\
(\mathrm{MPa})\end{array}$ & $\begin{array}{l}\text { Yield strength } \\
\quad(\mathrm{MPa})\end{array}$ & $\begin{array}{c}\text { Flexural } \\
\text { strength } \\
(\mathrm{MPa})\end{array}$ & $\begin{array}{c}\text { Elongation at } \\
\text { break (\%) }\end{array}$ \\
\hline FDM & Stratasys & $\begin{array}{l}\text { Fortus } \\
450 \mathrm{c}\end{array}$ & $406 \times 355 \times 406$ & $0.13-0.33$ & Polylactic Acid & 0.06 & 37 & $\mathrm{n} / \mathrm{a}$ & 62 & 4.4 \\
\hline $\begin{array}{l}\text { Metal FDM } \\
\text { /Material } \\
\text { extrusion }\end{array}$ & Markforged & Metal X & $300 \times 220 \times 180$ & $0.05-0.20$ & Fibre glass & 0.20 & 590 & $\mathrm{n} / \mathrm{a}$ & 210 & 3.8 \\
\hline SLS & EOS & P396 & $340 \times 340 \times 600$ & $0.06-0.18$ & $\begin{array}{l}\text { Polyamide } \\
\text { (PA2200) }\end{array}$ & 0.10 & 50 & $\mathrm{n} / \mathrm{a}$ & 52 & 20 \\
\hline SLS & 3D Systems & sP230 & $550 \times 550 \times 750$ & $0.08-0.15$ & $\begin{array}{l}\text { Polyamide } \\
\text { (DuraForm PA) }\end{array}$ & 0.10 & 43 & $\mathrm{n} / \mathrm{a}$ & 48 & 14 \\
\hline SLM & Renishaw & AM250 & $250 \times 250 \times 365$ & $0.02-0.10$ & Stainless steel 316L & 0.07 & $607-678$ & $480-550$ & $\mathrm{n} / \mathrm{a}$ & $27-45$ \\
\hline SLM & SLM Solutions & SLM 280 & $280 \times 280 \times 365$ & $0.02-0.075$ & Inconel 718 & 0.06 & $954-1034$ & $637-767$ & $\mathrm{n} / \mathrm{a}$ & $23-25$ \\
\hline EBM & GE Arcam & A2X & $200 \times 200 \times 380$ & $0.05-0.15$ & Ti-6Al-4V & 0.20 & 1020 & 950 & $\mathrm{n} / \mathrm{a}$ & 14 \\
\hline MJP & 3D Systems & $\begin{array}{l}\text { Projet } \\
\text { 860Pro }\end{array}$ & $508 \times 381 \times 229$ & 0.10 & $\begin{array}{l}\text { Visijet PXL } \\
\text { composite }\end{array}$ & 0.26 & 26.4 & $\mathrm{n} / \mathrm{a}$ & 44.1 & 0.21 \\
\hline
\end{tabular}

Acronyms: Fused Deposition Modelling (FDM), Selective Laser Sintering (SLS), Selective Laser Melting (SLM), Electron Beam Melting (EBM), MultiJet Printing (MJP), n/a in here means the data is not published by the manufacturer. In the methodology, if the relevant data is $\mathrm{n} / \mathrm{a}$, it is considered to be adequate. 
Table 5: Relative scale of criterion importance adapted from Saaty (2008)

\begin{tabular}{lcc}
\hline Scale & Numeric assessment & Reciprocal \\
\hline Extremely preferred & 9 & $1 / 9$ \\
Very, very strong & 8 & $1 / 8$ \\
Very strong & 7 & $1 / 7$ \\
Strong plus & 6 & $1 / 6$ \\
Strong preferred & 5 & $1 / 5$ \\
Moderate plus & 4 & $1 / 4$ \\
Moderately preferred & 3 & $1 / 3$ \\
Weak plus & 2 & $1 / 2$ \\
Equally preferred & 1 & 1 \\
\hline
\end{tabular}


Table 6: Assessment of comparative performance of commercial AM machines

\begin{tabular}{|c|c|c|c|c|c|c|}
\hline Selection criterion & FDM & SLM & SLS & MJP & EBM & HSS \\
\hline Accuracy & Average & Excellent & Excellent & Good & Low & Good \\
\hline Tensile strength & Good & Excellent & Excellent & Good & Excellent & Good \\
\hline Yield strength & Good & Excellent & Excellent & Good & Excellent & Good \\
\hline Flexural strength & Excellent & Average & Excellent & Excellent & Average & Good \\
\hline Elongation at break & Excellent & Excellent & Excellent & Excellent & Excellent & Good \\
\hline Build volume & Good & Good & Good & Excellent & Excellent & Excellent \\
\hline
\end{tabular}

Acronyms: Fused Deposition Modelling (FDM), Selective Laser Melting (SLM), Selective Laser Sintering (SLS), Multijet Printing (MJP), Electron Beam Melting (EBM), High Speed Sintering (HSS) 
Table 7: Selected features in the feature set for design modification assistance

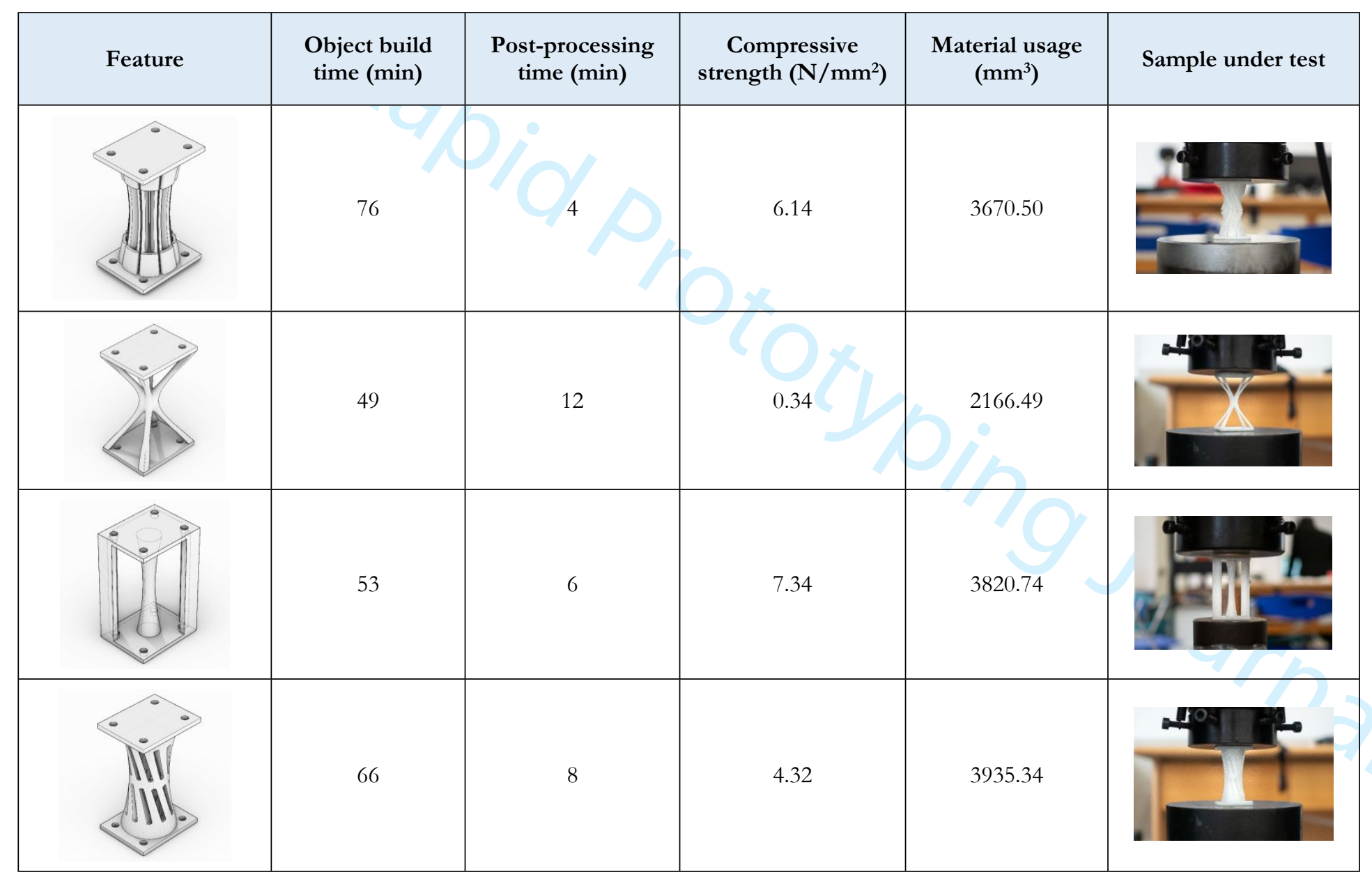


Table 8: Importance scale for the component of the exhaust gas duct

\begin{tabular}{l|lllll|l}
\hline & Material availability & Tensile strength & Build volume & $\begin{array}{l}\text { Dimensional } \\
\text { accuracy }\end{array}$ & $\begin{array}{l}\text { Multiple colour } \\
\text { printability }\end{array}$ & $\begin{array}{l}\text { Criterion } \\
\text { weight }\end{array}$ \\
\hline Material availability & 1 & 9 & 6 & 9 & 9 & 0.565 \\
Tensile strength & $1 / 9$ & 1 & $1 / 3$ & 6 & 9 & 0.150 \\
Build volume & $1 / 6$ & 3 & 1 & 6 & 9 & 0.205 \\
Dimensional accuracy & $1 / 9$ & $1 / 6$ & $1 / 6$ & $1 / 3$ & 1 & 0.050 \\
Multiple colour printability & $1 / 9$ & $1 / 9$ & $1 / 9$ & 22.33 & 31.00 & 0.029 \\
Sum & 1.50 & 13.28 & 7.61 & & & 1.000 \\
\hline
\end{tabular}


Table 9: Estimation of manufacturing costs for the component of the exhaust gas duct

\begin{tabular}{ll}
\hline AM machine & Estimated manufacturing cost per part (\$) \\
\hline 3D Systems DMP320 & 343.77 \\
3D Systems DMP500 & 576.87 \\
EOSINT M290 & 317.14 \\
EOSINT M400 & 525.81 \\
GE Arcam A2X & 779.63 \\
Renishaw AM250 & 220.26 \\
Renishaw AM500 & 516.93 \\
SLM Solutions SLM280 & 277.33 \\
SLM Solutions SLM500 & 540.25 \\
Aconity One & 490.62 \\
DMG Mori Lasertec 30 SLM & 313.87 \\
\hline
\end{tabular}

